\title{
CAMA
}

Centre for Applied Macroeconomic Analysis

\section{Technology transfer and North-South}

\section{CAMA Working Paper 18/2015 June 2015}

\section{Martin Davies}

Department of Economics, Washington and Lee University and

Centre for Applied Macroeconomic Analysis (CAMA), ANU

\begin{abstract}
Costless technology transfer is a standard assumption in the international trade literature, however by some estimates the average technology transfer cost is nearly $20 \%$ of total project costs (Teece, 1977). This analysis examines the conditions under which the advanced country gains when the transfer of technology from the advanced North to the less advanced South incurs resource costs. Results are derived for the effect on production, wages, prices and welfare of lower transmission and absorption costs, and productivity and population shocks. The framework is extended to examine the implications of an improvement in the enforcement of international intellectual property rights.
\end{abstract}




\section{Keywords}

\section{JEL Classification}

\section{Address for correspondence:}

(E) cama.admin@anu.edu.au

The Centre for Applied Macroeconomic Analysis in the Crawford School of Public Policy has been established to build strong links between professional macroeconomists. It provides a forum for quality macroeconomic research and discussion of policy issues between academia, government and the private sector.

The Crawford School of Public Policy is the Australian National University's public policy school, serving and influencing Australia, Asia and the Pacific through advanced policy research, graduate and executive education, and policy impact. 


\title{
Technology Transfer and North-South
}

\author{
Martin Davies* \\ Department of Economics, Washington and Lee University \\ and \\ Centre for Applied Macroeconomic Analysis, Australian National University
}

May 2015

\begin{abstract}
Costless technology transfer is a standard assumption in the international trade literature, however by some estimates the average technology transfer cost is nearly $20 \%$ of total project costs (Teece, 1977). This analysis examines the conditions under which the advanced country gains when the transfer of technology from the advanced North to the less advanced South incurs resource costs. Results are derived for the effect on production, wages, prices and welfare of lower transmission and absorption costs, and productivity and population shocks. The framework is extended to examine the implications of an improvement in the enforcement of international intellectual property rights.
\end{abstract}

*daviesm@wlu.edu 


\section{Introduction and Motivation}

To the joy of the anti-globalization lobby, and the chagrin of proponents of free trade, an influential paper by Samuelson (2004) argues that the transfer of Northern technology directed to the Southern importables sector facilitated by freer trade will diminish Ricardian comparative advantage and with it the gains from trade. In the extreme, if the transfer equalizes relative labour productivities between the North and South then the gains from trade are extinguished and welfare in the North is lowered to its autarkic level, while the South with improved technology will gain. ${ }^{1}$ In response to this dire possibility, Jones and Ruffin examine the conditions under which a country with superior technology may gain when making an uncompensated transfer of superior technology to a less advanced country in both 2-good (Jones and Ruffin, 2007) and n-good (Jones and Ruffin, 2008) settings. A common feature of these analyses is that there is no resource cost in the transfer of technology. Whether through gift, theft or technological diffusion, productive factors in the South are able to costlessly access and exploit Northern technology. In fact, the assumption that technology can be transferred costlessly between countries is prevalent throughout the international trade literature, an exception being Cheng, Qiu and Tan (2005).

However, technology transfer requires deliberate and costly action. Teece (1977) finds that the average technology transfer cost is nearly one-fifth of total project costs, where the cost of technology transfer is defined as the value of the resources which are required to transfer technology from plants in one country to those in another. In this paper we extend the trade and technology transfer literature by examining the situation in which there is an explicit resource cost of moving technology from one country to another. With this modification we examine the conditions under which technology transfer from the North to the South will benefit the advanced country. We also examine the effects of an improvement in intellectual property rights (IPR) on Northern and Southern welfare.

Following Teece, the activity of technology transfer involves the transmission and absorption of technology, and resource costs associated with each of these, which are mirrored in the structure of transfer costs in this paper. Absorption refers to the ability of the recipient to assimilate new technology and hence these costs are bourne by the South. Transmission costs, on the other hand, represent the cost of moving the superior technology from one location to another, and primarily

\footnotetext{
${ }^{1}$ Dornbush, Fisher and Samuelson (1977) also note that the advanced country must lose when the harmonization of relative unit labour requirements is complete.
} 
involve activities that engage resources in the advanced country. To simplify the analysis we assume this to be the case.

This extension has a number of advantages over analyses with costless technology transfer. Firstly, the commodities in which technology transfer takes place are endogenously determined. This differs from the two good analyses of Samuelson (2004) and Jones and Ruffin (2007) in which technology transfer from the North is directed to either the South's exportable or importable good, and the $n$-good model of Jones and Ruffin (2008) in which technology transfer occurs in an arbitrary good. Secondly, since technology transfer takes place in both the South's exportable and importable sectors, a shock which increases the ease of technology transfer leads to relocation of production of some commodities along with their technology from the North to the South; and also the exploitation of Northern technology by some, but not all, incumbent Southern exporters. This differs from the Samuelson and Jones and Ruffin analyses, which examine this shock as a technology transfer to either the South's importables or exportables sector. Thirdly, the transfer of Northern technology creates a role for Northern expertise to assist in the application of superior technology to Southern factors of production. This source of demand for Northern resources, which occurs along two margins, is overlooked when the costs of technology transfer are assumed away. When technology transfer leads to the relocation of production across borders, the requisite transmission costs generate a demand for Northern factors of production. In addition, Northern factors are required to assist producers in the Southern final good sector who choose to adopt superior Northern technology. Both of these sources mitigate the reduction in demand for Northern factors of production due to lost (relocated) production.

The resources engaged in technology transfer, and more generally in goods production, may be thought of as an amalgam of capital, skilled and unskilled labour, and managerial services. Viewing the single factor in this paper as a Leontief aggregate ${ }^{2}$ then this factor, which we call labour, may be thought of as a productive resource encompassing all of these factors. The Ricardian model is well suited to the analysis of technology transfer as technological differences, which are requisite for technology transfer, form the basis for trade.

Three of the primary channels through which technology transfer occurs across international boundaries are foreign direct investment (FDI), joint ventures, and licensing. While FDI is the dominant channel for transfer of technology between developed and developing countries, and con-

\footnotetext{
${ }^{2} \mathrm{~A}$ Leontief aggregate is a fixed ratio of quantities.
} 
tinues to grow in importance (Glass and Saggi, 2008) for the purpose of this paper we find no need to distinguish between different modes of transfer. Regardless of the mode of transfer resource costs must be incurred to move technology from one location to another.

Within this framework we examine the impact of lower absorption and transmission costs on production, wages, prices and welfare. The impact on the technology transfer equilibrium of productivity improvement in the final goods sectors of the South and the North, and also a population shock, are also determined. There are a number of channels which may lead, through the conduits of international trade and FDI, productivity levels between countries to be interrelated. We examine the possibility that technology transfer to the South might lead to spillovers, and establish a condition to determine the equilibrium at which the total benefit from spillovers is maximized. Finally we examine impact of better enforcement of intellectual property rights on Northern and Southern welfare.

This paper is organized as follows. Section 2 provides a brief examination of related literature. Section 3 presents the model, and Section 4 provides analysis on the impact for a variety of shocks. Section 5 examines the implications of technology transfer for prices and welfare and Section 6 extends the model to look at the effects of an improvement in intellectual property rights on welfare. Section 7 concludes.

\section{Literature}

Samuelson (2004) examines the progression from autarky to free trade, and then the impact on the free trade equilibrium of productivity shocks to the export and import sectors of the less advanced country in a textbook two-good two-country Ricardian model using simple numerical examples. While the productivity improvement in the export sector makes both countries better off, the import shock makes the advanced country worse off. Jones and Ruffin (2007, 2008) examine the impact of an unrequited technology gift from an advanced home country with superior technology to a less advanced foreign country. Jones and Ruffin (2007), also using the textbook Ricardian model, find that an unrequited transfer has the following implications. A transfer of the import-competing technology will always benefit the home country as the pattern of comparative advantage is maintained and the terms of trade improve. When the home country transfers all of its technology to the foreign country there is no comparative advantage, and home's welfare falls 
to the autarkic level. Finally if the home country transfers the exportable technology, then the pattern of comparative advantage is reversed. Since home has an absolute advantage in the original importable, and unit labour requirements are equalized in the original exportable, then the home country now has a comparative advantage in the original importable. The home country may lose or gain from this situation.

In Jones and Ruffin (2008) the impact of an uncompensated technology transfer sufficient to drive the advanced country out of producing its best export good is examined in an $n$-good twocountry Ricardian framework. When the equilibrium is located at a turning point such that the advanced home country is incipiently producing a commodity, while the less advanced foreign country supplies the entire world market of that commodity, then the relative wage is unaffected by a transfer of technology. The advanced country now shares the market for that good with the foreign country, which pins down the relative wage. The improvement in the foreign country's technology lowers the price level, leading to an increase in home's real wage and welfare. When the equilibrium is not at a turning point a transfer of technology will lead the foreign country's wage to rise. Although this leads to a fall in the price of the good whose technology was transferred, the price of home's other imports rises and the effect of home welfare is ambiguous.

Teece (1977) examines the determinants of the costs of transferring technology. Using data from 26 international technology transfer projects four groups of transfer costs are identified. These are: i. cost of pre-engineering technological change; ii. engineering costs associated with transferring the process design or product design; iii. costs of $\mathrm{R} \& \mathrm{D}$ personnel for adapting/modifying the technology and solving unexpected problems during all phases of the transfer project, and iv. prestart-up training costs, and learning and debugging costs during the start-up phase. From the sample, transfer costs average $19 \%$ of total project costs, with a range between $2 \%$ and $59 \%$. Teece makes a distinction between transmission and absorption costs which is mirrored in the structure of resource costs of technology transfer in this paper. Absorption costs refer to the ability of the recipient to absorb the new technology, which depend on both the recipient and host country characteristics. When technology is complex and the recipient lacks the capacity to absorb the new technology then the cost of transfer may be considerable. A related issue is whether resources need to be devoted to building up absorptive capacity, as first discussed in Cohen and Levinthal (1989). Leahy and Neary (2007) examine the theoretical implications of investment in absorptive capacity. 
The structure of the model in this paper is similar to that presented by Cheng et. al. (2005) with a simple, yet significant, modification. While in Cheng et. al. the transmission of technology is facilitated by an additional factor called expatriate workers which has no productive value in any alternative use, and does not consume goods nor enter welfare calculations, here Northern labour is engaged in this role. The resources used in the transmission of technology have an opportunity cost: their value in the production of final goods in the North. The benefit of this modification is that the model solves for a full general equilibrium. All productive activities including technology transfer enter the relative demand for labour, and the relative supply of labour encompasses all resources. Further, the boundaries which divide the goods continuum, between the South's final goods sector, the technology transfer sector and the North's final goods sector depend on, and will respond to changes in, the relative scarcity of labour.

Mussa (1978) examines the movement of capital between sectors when there is a resource cost to do so in a two-good two-factor Heckscher-Ohlin-Samuelson economy facing external goods prices. The resource cost includes intersectorally mobile labour and a factor specific to the capital movement industry. The competitive adjustment path is determined in response to a price shock for both static and rational expectations.

Krugman (1979) examines product cycle trade when innovations which create new products occur at an exogenous rate in the developed North, and there is transfer of technology of new goods from the North to the South also at an exogenous rate. The basis for trade is the technological lag, with the North producing and exporting new products, and the South producing and exporting only old products. Technology transfer is costless and once a blueprint becomes available to the South, it is able to produce the good with productivity equal to that in the North.

Grossman and Rossi-Hansberg (2008), Baldwin and Robert-Nicoud (2007) and Rodriguez-Clare (2010) all present models of offshoring of tasks. Tasks are the units of the building blocks of final goods, and different factor-tasks are substitutable, reflecting factor substitution. Offshoring of a particular task involves the application of home technology to cheaper foreign factors, and hence these models make the assumption, whether implicit or explicit, that home technology may be transferred, without explicit cost, for use by foreign factors. 


\section{Model}

There is a continuum of goods on $[0,1]$, ordered according to increasing technological sophistication with higher numbers indicating higher sophistication, as in Young (1991). Two countries, North and South, are each endowed with a single productive factor called labour, $L^{N}$ and $L^{S}$. For simplicity, Southern labour is defined as the numeraire, and the relative price of labour, the North's wage, is defined as $w$. To facilitate its role in the transmission of technology Northern labour is internationally mobile, while Southern labour is immobile.

\subsection{Production}

Production technology in the North and the South is defined as

$$
\begin{aligned}
y^{N}(j) & =L^{N}(j) \\
y^{S}(j) & =\frac{L^{S}(j)}{a(j)}
\end{aligned}
$$

where units of goods are defined such that Northern unit labour requirements are unity for all $j$, and $a(j)$ represents the unit labour requirements for the South. It is assumed that the North has an absolute advantage in all goods except the simplest, $j=0$ : thus $a(j)>1$ for all $j>0$ and $a(0)=1$. In addition, the North has a comparative advantage in sophisticated goods, and $a(j)$ is increasing in $j$.

\subsection{Technology Transfer Sector}

Goods may be produced in the South using Northern technology. Similar to Cheng et. al. (2005), to produce a good using Northern technology requires, in addition to an input of Southern labour, an input of Northern labour which represents the transmission cost of technology transfer. The Northern resource requirement for good $j$ is $a_{T}(j)=\gamma+\tilde{a}_{T}(j)$, with $\gamma$ and $\tilde{a}_{T}(j)$ representing the fixed and variable components of the transmission costs. The variable component, $\tilde{a}_{T}(j)$, has the following properties:

i. $\quad \tilde{a}_{T}(j)$ is continuous and twice differentiable in $j$, and $\tilde{a}_{T}^{\prime}(j)>0, \tilde{a}_{T}^{\prime \prime}(j) \geqslant 0$.

ii. $\quad \tilde{a}_{T}(0)=0$

iii. $\tilde{a}_{T}(1) \geqslant 1-\gamma$

Property i. imposes that the transmission costs increase at a non-decreasing rate in sophistica- 
tion. This is intuitive as the technology of more sophisticated goods is more complex, and transfer of it requires more resources. Property iii. ensures in equilibrium that there is a Northern final goods sector $\left(z_{1}<1\right)$. The unit labour requirement of Southern labour in technology transfer is $e=1+\varepsilon$, where $\varepsilon>0$ is the absorption cost. This reflects costs of production beyond Northern technology, which has a unit labour requirement of one, since the South is unable to fully absorb and exploit the technology from the North due to a lack of infrastructure, and language, cultural and attitudinal differences. Technology is Leontief with a unit of good $j$ requiring $e$ units of Southern labour and $a_{T}(j)$ units of Northern labour, and is represented by

$$
y(j)=\min \left[\frac{L^{S}(j)}{e}, \frac{L^{N}(j)}{a_{T}(j)}\right]
$$

with the unit cost of goods produced using transferred technology ${ }^{3}$

$$
b(j)=1+\varepsilon+w a_{T}(j)
$$

\subsection{Consumption}

Households consume a continuum of final goods indexed by the variable $j$ over the interval $[0,1]$ and have identical homothetic preferences $\ln U=\int_{0}^{1} \ln y(j) d j$, where $y(j)$ is the consumption of final good $j$. The consumer solves the problem $\max _{y(j)} \int_{0}^{1} \ln y(j) d j$ subject to $\int_{0}^{1} p(j) y(j)=Y$. World demand for good $j$ is $\left(w L^{N}+L^{S}\right) / p(j)$, where world income is $w L^{N}+L^{S}$. This leads to the first result.

Lemma 1 The utility per capita is equal to the real wage, where $\ln \left(U^{N} / L^{N}\right)=\ln (w / P)$ and $\ln \left(U^{S} / L^{S}\right)=\ln (1 / P)$, where $\ln P=\int_{0}^{1} \ln p(j) d j$ is the true price index.

Proof. The proof is in the Appendix.

\subsection{Technology Transfer Equilibrium}

In order to ensure a well-behaved equilibrium we make the following two assumptions:

(A1) Single Crossing: $a(z)-b(z)$ crosses zero only once, strictly from below.

$$
a^{\prime}\left(z_{0}\right)>\left.\frac{\partial b(z)}{\partial z}\right|_{z_{0}}=w \tilde{a}_{T}^{\prime}\left(z_{0}\right)
$$

\footnotetext{
${ }^{3}$ In terms of the definition of the cost of technology transfer given by Teece (1977), $w a_{T}(j)$ represents the transmission cost, and $\varepsilon$ the absorption cost, both measured in units of Southern labour.
} 
(A2) Convexity: ${ }^{4}$

$$
\frac{d}{d w}\left(\left.\frac{d z_{0}}{d w}\right|_{d \varepsilon, d \gamma=0}\right)=\frac{d}{d w}\left(\frac{\tilde{a}_{T}\left(z_{0}\right)}{a^{\prime}\left(z_{0}\right)-w \tilde{a}_{T}^{\prime}\left(z_{0}\right)}\right) \geqslant 0
$$

Assumption (A1) ensures that technology transfer takes place over a contiguous interval of the goods continuum. (A2) is required to establish an equilibrium, as will be demonstrated below. Assuming perfect competition, the price of good $j$ in the North is $p(j)=w$, and in the South is $p(j)=a(j)$. Goods may also be produced in the technology transfer sector at cost $b(j)=e+w a_{T}(j)$. Given the ordering of goods, and the assumptions about the resource costs of technology transfer, the following two equations determine the boundaries of production location, $z_{0}$ and $z_{1}$.

$$
\begin{aligned}
a\left(z_{0}\right) & =b\left(z_{0}\right)=e+w\left(\gamma+\tilde{a}_{T}\left(z_{0}\right)\right) \\
w & =b\left(z_{1}\right)=e+w\left(\gamma+\tilde{a}_{T}\left(z_{1}\right)\right)
\end{aligned}
$$

Production is allocated as demonstrated in Figure 1. The point $\alpha$ indicates the boundary between the South's final goods sector and the technology transfer sector, determined by (2), and $\beta$ indicates the boundary between the technology transfer sector and the North's final goods sector, determined by (3). It follows that goods on the interval $\left[0, z_{0}\right)$ are produced in the South; goods on the interval $\left[z_{1}, 1\right]$ are produced in the North; and goods on $\left[z_{0}, z_{1}\right)$ are produced in the South using Northern technology and both Northern and Southern labour. Because there is a resource cost of technology transfer, transfer does not occur in goods for which comparative advantage is strongest: the simplest goods for the South and the most sophisticated goods for the North.

[Figure 1 about here]

\subsection{Pre-technology Transfer Equilibrium}

The Ricardian continuum framework forms the basis for part of the solution to the model, and also represents the solution to the pre-technology transfer equilibrium, and is presented briefly. The comparative advantage locus is

$$
w=a(z)
$$

\footnotetext{
${ }^{4}$ This assumption requires that $z_{1 w w}=2 \tilde{a}_{T}^{\prime}\left(z_{0}\right)\left(a^{\prime}\left(z_{0}\right)-w \tilde{a}_{T}^{\prime}\left(z_{0}\right)\right)-a_{T}\left(z_{0}\right)\left(\tilde{a}^{\prime \prime}\left(z_{0}\right)-w \tilde{a}_{T}^{\prime \prime}\left(z_{0}\right)\right) \geqslant 0$ which is satisfied when $a^{\prime \prime}\left(z_{0}\right) \leqslant w \tilde{a}_{T}^{\prime \prime}\left(z_{0}\right)$. When $a(j)$ and $\tilde{a}_{T}(j)$ are linear in $j$, the inequality holds strictly as $a^{\prime \prime}(j)$ and $\tilde{a}_{T}^{\prime \prime}(j)$ are both zero.
} 
Labour market equilibrium in the South is determined by $L^{S}=z w L^{N}+z L^{S}$, which when rearranged gives an equation for the balance of trade

$$
w=\left(\frac{1-z}{z}\right) \lambda
$$

where $\lambda=L^{S} / L^{N}$. This may be interpreted as the wage which ensures trade balance when the cutoff good is $z$. At this point trade is balanced and the location of production is efficient. Inverting (4) so that $z=a^{-1}(w)=z(w)$ where $z^{\prime}(w)>0$ and substituting into (5) the equilibrium may be expressed

$$
w=h_{D F S}(w)=\left(\frac{1-z(w)}{z(w)}\right) \lambda
$$

which is one equation in one unknown, $w$. For each value of $\lambda \in(0, \infty)$ there is a unique solution to the DFS-benchmark model denoted by $\left(z_{D}(\lambda), w_{D}(\lambda)\right)$. As $\lambda$ increases the equilibrium wage and cut off good, $w_{D}$ and $z_{D}$, increase.

\subsection{Balance of Trade with Technology Transfer}

The South engages in two types of productive activity. It produces final goods on $\left[0, z_{0}\right)$ using Southern technology, and it provides labour which is combined with Northern resources and technology to produce goods on $\left[z_{0}, z_{1}\right)$. We separate the total demand for Southern labour into $L_{D 1}^{S}$ and $L_{D 2}^{S}$, corresponding to the sub-intervals $\left[0, z_{0}\right)$ and $\left[z_{0}, z_{1}\right)$. The demand for Southern labour to produce a good $j$ on $\left[0, z_{0}\right)$ is $L_{D 1}^{S}(j)=a(j) y(j)=Y$. The total demand for Southern labour to produce goods $j \in\left[0, z_{0}\right)$ is $L_{D 1}^{S}=\int_{0}^{z_{0}} Y=z_{0} Y$. On the interval $\left[z_{0}, z_{1}\right)$ each unit of good $j$ requires the input of $e$ units of Southern labour and $a_{T}(j)$ units of Northern labour according to (1). Since the output of good $j$ is $y(j)=Y /\left(e+w a_{T}(j)\right)$ then the South's derived demand for labour for good $j$ in the technology transfer sector is $L_{D 2}^{S}(j)=e Y /\left(e+w a_{T}(j)\right)$. Integrating over $\left[z_{0}, z_{1}\right)$ yields

$$
L_{D 2}^{S}=z_{1} Y-z_{0} Y-Y \int_{z_{0}}^{z_{1}} \frac{w a_{T}(j)}{e+w a_{T}(j)} d j
$$

which gives the total demand for Southern labour in the technology transfer sector. We define for convenience the following: $\theta(j)=w a_{T}(j) /\left(e+w a_{T}(j)\right)$ and $\Theta\left(w, z_{0}, z_{1}\right)=\int_{z_{0}}^{z_{1}} \theta(j) d j$, where $\theta(j)$ is the North's factor share in good $j$, and $\Theta\left(w, z_{1}, z_{0}\right)$ represents the North's average factor share in technology transfer. ${ }^{5}$ Equating the total demand for Southern labour, $L_{D 1}^{S}+L_{D 2}^{S}$, with the supply

\footnotetext{
${ }^{5}$ This is calculated as an arithmetic average where the weights are expenditure shares.
} 
of Southern labour, $L^{S}$, gives the South's labour market equilibrium $L^{S}=\left(z_{1}-\Theta\left(w, z_{0}, z_{1}\right)\right) Y$. This may be written

$$
w=\left(\frac{1-\left(z_{1}-\Theta\left(w, z_{0}, z_{1}\right)\right)}{z_{1}-\Theta\left(w, z_{0}, z_{1}\right)}\right) \lambda
$$

and which determines the relative wage, $w$, which for given $z_{0}$ and $z_{1}$ yields balance of trade. ${ }^{6}$

\subsection{Model with Technology Transfer}

The model is expressed as three equations, (2), (3), and (7) in three unknowns, $w, z_{0}$, and $z_{1}$. Equations (2) and (3) may be used to determine the responses of $z_{0}$ and $z_{1}$ to changes in the relative wage $w$, the absorption $\operatorname{cost} \varepsilon$, and transmission $\operatorname{costs} \gamma$. Applying (A1) it follows that ${ }^{7}$

$$
\begin{aligned}
z_{0} & =z_{0}\left(\begin{array}{c}
w, \varepsilon, \gamma \\
+++
\end{array}\right) \\
z_{1} & =z_{1}(\underset{+}{w}, \underline{\varepsilon}, \gamma)
\end{aligned}
$$

From (A2), $z_{0 w w} \geqslant 0$ which ensures that $z_{0}$ increases at a non-decreasing rate in $w,{ }^{8}$ and since $z_{1 w w}<0$ then $z_{1}$ is increasing at a decreasing rate in $w$.

\section{[Insert Figure 2 here]}

Using these properties the functions $z_{0}(w, \varepsilon, \gamma)$ and $z_{1}(w, \varepsilon, \gamma)$ are drawn in Figure 2 for given $\varepsilon$ and $\gamma$. Since $z_{0 \varepsilon}>0$ and $z_{1 \varepsilon}<0$ then as $\varepsilon$ falls the $z_{0}($.$) locus shifts to the left and the z_{1}($. locus shifts to the right. Similarly since $z_{0 \gamma}=w /\left(a^{\prime}\left(z_{0}\right)-w \tilde{a}_{T}^{\prime}\left(z_{0}\right)\right) \geqslant 0$ and $z_{1 \gamma}<0$, a fall in $\gamma$ rotates the $z_{0}($.$) upward around its vertical intercept z_{0}=a^{-1}(e),{ }^{9}$ and shifts the $z_{1}($.$) locus$ right. Hence the impact of $\varepsilon$ and $\gamma$ have offsetting effects on the positions of the $z_{0}($.$) and z_{1}($. loci. For example, an increase in $\varepsilon$ shifts the $z_{0}($.$) locus left and z_{1}($.$) locus to the right, and a fall$ in $\gamma$ does the reverse.

Lemma 2 When $\varepsilon=0$ the value of $\gamma$ which ensures tangency between $z_{0}(w, \varepsilon, \gamma)$ and $z_{1}(w, \varepsilon, \gamma)$ is $\bar{\gamma}$. For $\gamma<\bar{\gamma}$ there exists a value of $\varepsilon>0$, defined as $\varepsilon^{*}(\gamma)$ at which there is tangency between $z_{0}(w, \varepsilon, \gamma)$ and $z_{1}(w, \varepsilon, \gamma)$.

Proof. The proof is in the Appendix.

\footnotetext{
(5).

${ }^{6}$ When there is no technology transfer, so that $z_{1}=z_{0}$, then $\Theta\left(w, z_{0}, z_{1}\right)=0$ and the balance of trade reduces to ${ }^{7}$ See the Appendix for calculation of these terms.

${ }^{8} \mathrm{~A}$ sufficient condition for $(A 2)$ is that $a^{\prime \prime}\left(z_{0}\right) \leqslant w L_{T}^{\prime \prime}\left(z_{0}\right)$

${ }^{9}$ Since at $w=0$ then $z_{0 \gamma}=0$.
} 
This result establishes that when $\varepsilon$ and $\gamma$ are zero then there is region of the goods continuum where technology transfer will take place, and demonstrates the trade-off between $\gamma$ and $\varepsilon$ in terms of their influences on the position of the $z_{0}($.$) and z_{1}($.$) loci.$

Lemma 3 When $\gamma \geq \bar{\gamma}$, or $\varepsilon \geq \varepsilon^{*}(\gamma)$ for $\gamma<\bar{\gamma}$, there is no technology transfer, and the solution to the model is given by the DFS benchmark.

Proof. The proof is in the Appendix.

Under these parameter values the $z_{0}($.$) and z_{1}($.$) loci are tangent, as in Figure 3$, or non-touching and technology transfer cannot occur.

[Figure 3 about here]

Lemma 4 When $\gamma \in[0, \bar{\gamma})$ and $\varepsilon \in\left[0, \varepsilon^{*}(\gamma)\right)$ there are two points of intersection between $z_{0}(w, \varepsilon, \gamma)$ and $z_{1}(w, \varepsilon, \gamma)$ on $[0,1)$, which are defined $\left(z_{L}\left(w_{L}\right), w_{L}\right)$ and $\left(z_{H}\left(w_{H}\right), w_{H}\right)$. Associated with each point of intersection is a relative labour endowment, $\lambda_{L}(\varepsilon, \gamma)$ and $\lambda_{H}(\varepsilon, \gamma)$ respectively. Conditions for technology transfer require that $\gamma \in[0, \bar{\gamma}), \varepsilon \in\left[0, \varepsilon^{*}(\gamma)\right)$ and $\lambda \in\left(\lambda_{L}(\varepsilon, \gamma), \lambda_{H}(\varepsilon, \gamma)\right)$.

Proof. The proof is in the Appendix.

For technology transfer to take place, transmission and absorption costs together cannot be too high and the relative labour supply cannot be too high or too low, lying within the 'Goldilocks' region defined above, which is determined by $\varepsilon$ and $\gamma$.

Definition 1 When $\gamma \in(0, \bar{\gamma}), \varepsilon \in\left(0, \varepsilon^{*}(\gamma)\right)$ and $\lambda$ is either $\lambda_{L}(\varepsilon, \gamma)$ or $\lambda_{H}(\varepsilon, \gamma)$, or when $\gamma \in(0, \bar{\gamma}), \varepsilon=\varepsilon^{*}(\gamma)$ and $\lambda^{*}(\varepsilon, \gamma)$, then technology transfer is incipient. ${ }^{10}$

In the first case the $z_{0}($.$) and z_{1}($.$) loci intersect, and the relative labour supplies \lambda_{L}(\varepsilon, \gamma)$ and $\lambda_{H}(\varepsilon, \gamma)$ ensure equilibrium points such that technology transfer is just prevented. In the second case $z_{0}($.$) and z_{1}($.$) are tangent, as in Figure 3, and the relative labour supply \lambda^{*}(\varepsilon, \gamma)$ ensures the equilibrium point is at the point of tangency $\left(z^{*}, w^{*}\right)$.

\footnotetext{
${ }^{10}$ The value $\gamma=\bar{\gamma}$ is excluded from this definition because $\varepsilon(\bar{\gamma})=0$ and it is not possible to examine a fall in $\varepsilon$ from $\varepsilon=0$.
} 


\subsection{Solution of Model with Technology Transfer}

Substituting (8) and (9) into (7) gives

$$
w=\left(\frac{1-\left(z_{1}(w, \varepsilon, \gamma)-\Theta\left(w, z_{0}(w, \varepsilon, \gamma), z_{1}(w, \varepsilon, \gamma)\right)\right)}{z_{1}(w, \varepsilon, \gamma)-\Theta\left(w, z_{0}(w, \varepsilon, \gamma), z_{1}(w, \varepsilon, \gamma)\right)}\right) \lambda
$$

which is one equation in one unknown, $w$, and determines the equilibrium to the model when there is technology transfer. Defining the $R H S$ of $(10)$ as $h_{T T}(w, \varepsilon, \gamma) \lambda$, the equilibrium of the model is determined by $w=h(w, \varepsilon, \gamma) \lambda$ where

$$
h(w, \varepsilon, \gamma) \lambda=\left\{\begin{array}{l}
h_{T T}(w, \varepsilon, \gamma) \lambda \text { for } \lambda \in\left(\lambda_{L}(\varepsilon, \gamma), \lambda_{H}(\varepsilon, \gamma)\right) \\
h_{D F S}(w) \lambda \text { for } \lambda \leqslant \lambda_{L}(\varepsilon, \gamma), \lambda \geqslant \lambda_{H}(\varepsilon, \gamma)
\end{array}\right.
$$

since from Lemma 4 the solution to the model is given by the DFS benchmark for $\lambda \leqslant \lambda_{L}(\varepsilon, \gamma), \lambda \geqslant$ $\lambda_{H}(\varepsilon, \gamma)$. From Lemma 1, a unique equilibrium is ensured for $\lambda$ on this range. To ensure the existence of a unique equilibrium for $\lambda \in\left(\lambda_{L}(\varepsilon, \gamma), \lambda_{H}(\varepsilon, \gamma)\right)$ it is sufficient to show that $h_{T T w}(w, \varepsilon, \gamma)<0$ in the relevant range.

Unique Equilibrium A unique equilibrium is assured when an increase in the North's relative wage leads to an increase in the South's share of world income, $\left(z_{1}-\Theta\right)$, which is the denominator of (10). ${ }^{11}$ As the wage increases there is adjustment to $\left(z_{1}-\Theta\right)$ on three margins. Firstly, the North's extensive margin, $z_{1}$, contracts shifting goods into the technology transfer sector and increasing the South's share of world income by $\left(1-\theta\left(z_{1}\right)\right) z_{1 w}$, represented by area $d$ in Figure 4 .

[Figure 4 about here]

An increase in the wage also increases the extensive margin of Southern production, $z_{0}$, which moves goods from the technology transfer sector to the South and increases the South's share of world income by $\left.\theta\left(z_{0}\right)\right) z_{0 w}$ (area $b$ ). Finally the rise in $w$ decreases the South's intensive margin in the technology transfer sector which reduces the South's share of world income by the third term in $(12)(\operatorname{area} a)$. The overall effect on the South's share of world income, and thus the relative demand for Southern labour, of an increase in $w$ depends on the sum of these terms

$$
z_{1 w}-\Theta_{w}=\left(1-\theta\left(z_{1}\right)\right) z_{1 w}+\theta\left(z_{0}\right) z_{0 w}-\frac{e}{w} \int_{z_{0}}^{z_{1}} \frac{\theta(j)}{b(j)} d j
$$

The equilibrium locus $h_{T T}(w, \varepsilon, \gamma) \lambda$ is anchored at $\left(w_{L}, h_{D F S}\left(w_{L}\right) \lambda_{L}\right)$ and $\left(w_{H}, h_{D F S}\left(w_{H}\right) \lambda_{H}\right)$,

\footnotetext{
${ }^{11}$ Since $h(w, \varepsilon, \gamma)=\left(1-\left(z_{1}-\Theta\right)\right) /\left(z_{1}-\Theta\right)$ then $\operatorname{sign}\left|h_{w}(w, \varepsilon, \gamma)\right|=-\operatorname{sign}\left|z_{1 w}-\Theta_{w}\right|$. Hence $h_{w}(w, \varepsilon, \gamma)<0$ requires $z_{1 w}-\Theta_{w}>0$.
} 
as drawn in Figure 5. ${ }^{12}$

[Figure 5 about here]

It is also negatively sloped at these points because $h_{T T w}\left(w_{i}, \varepsilon, \gamma\right)<0$ for $i=L, H$ as the third term in (12) is zero. ${ }^{13}$ For $w \in\left(w_{L}, w_{H}\right)$ the third term in (12) is positive because there is technology transfer and $z_{1}>z_{0}$, which leads to the possibility that $h_{T T w}(w, \varepsilon, \gamma)$ might become positive for some $w \in\left(w_{L}, w_{H}\right)$. We henceforth make assumption $(A 3)$ that $z_{1 w}-\Theta_{w}>0$ for all $w \in\left(w_{L}, w_{H}\right)$ which ensures a unique equilibrium. It is not possible to establish whether the slope of $h_{T T}(w, \varepsilon, \gamma) \lambda$ is greater or less than the slope of $h_{D F S}(w) \lambda$ at $w_{L}$ and $w_{H} \cdot{ }^{14}$

\section{Shocks}

\subsection{Population Shock}

An increase in $\lambda$ shifts the $h(w, \varepsilon, \gamma) \lambda$ locus upward for any given $w$ without altering $w_{L}$ or $w_{H}$ as in Figure $6 .{ }^{15}$ The relative wage increases, and it follows from (8) and (9) that both $z_{0}$ and $z_{1}$ increase. The effect on the size of the technology transfer sector is examined in the next result.

[Figure 6 about here]

Lemma 5 When $\varepsilon \in\left[0, \varepsilon^{*}(\gamma)\right)$ and $\lambda \in\left(\lambda_{L}(\varepsilon, \gamma), \lambda_{H}(\varepsilon, \gamma)\right)$ there exists a relative labour endowment $\lambda_{m}$ and a corresponding equilibrium $\left(z_{0}^{m}, z_{1}^{m}, w_{m}\right)$ at which technology transfer is maximized.

Proof. The proof is in the Appendix.

This equilibrium is drawn in Figure 2. At one extreme, when Northern labour is relatively abundant and the North's relative wage is very low, it is cheaper for the North to produce all goods above $z_{0}$ than to engage Southern labour in technology transfer. At the other extreme, when Northern labour is very expensive it is cheaper for the South to produce all goods below $z_{1}$ rather than to employ Northern labour in the technology transfer sector.

\footnotetext{
${ }^{12}$ This is drawn for the linear case $\left(a(j)=1+j, b(j)=e+w(\gamma+j / 2)\right.$, which is interesting because $h_{T T}(w, \varepsilon, \gamma) \lambda$ is steeper at both $w_{L}$ and $w_{H}$ and hence there is both a point on $\left(w_{L}, w_{H}\right)$ where $h_{T T}(w, \varepsilon, \gamma) \lambda$ and $h_{D F S}(w) \lambda$ intersect, and also a point of inflexion.

${ }^{13}$ At $\left(w_{i}, h_{D F S}\left(w_{i}\right) \lambda_{i}\right)$ for $i=L, H$, since $z_{0}=z_{1}=z$ then $z_{1 w}-\Theta_{w}=\left(1-\theta\left(z_{i}\right)\right) z_{1 w}+\theta\left(z_{i}\right) z_{0 w}>0$ and thus $h_{w}\left(w_{i}, \varepsilon, \gamma\right)<0$.

${ }^{14}$ At $w_{i}(i=L, H)$ it is the case that $h_{D F S_{w}}\left(w_{i}\right)=-z^{\prime}\left(w_{i}\right) / z\left(w_{i}\right)^{2}$ and $h_{T T w}\left(w_{i}, e\right)=$ $-\left((1-\theta(z)) z_{1 w}+\theta(z) z_{0 w}\right) / z\left(w_{i}\right)^{2}$. At $w_{L}, z_{1 w}\left(w_{L}\right)>z^{\prime}\left(w_{L}\right)>z_{0 w}\left(w_{L}\right)$ and at $w_{H}, z_{1 w}\left(w_{H}\right)<z^{\prime}\left(w_{H}\right)<$ $z_{0 w}\left(w_{H}\right)$. Since $v_{w}$ is a weighted average of $z_{1 w}(w)$ and $z_{0 w}(w)$, it is not possible to determine at either of these points whether $(1-\theta(z)) z_{1 w}+\theta(z) z_{0 w} \gtreqless z^{\prime}\left(w_{i}\right)$.

${ }^{15}$ The points $w_{L}$ and $w_{H}$ are determined purely by technology and are not influenced by the demand side.
} 
If population growth in the South is higher than in the North ( $\lambda$ is increasing) this drives up the price of Northern labour, pushing up $z_{1}$ and $z_{0}$. As $\lambda_{H}$ is approached $z_{1 w}$ is falling and $z_{0 w}$ is increasing and the size of the technology transfer sector, $z_{1}-z_{0}$, is contracting. At $\lambda_{H}$ the relative wage has risen enough to extinguish technology transfer. This result runs counter to mercantilist intuition, which might be stated as something like more abundant Southern labour increases the incentive for the North to direct resources to transfer technology to the South to exploit the opportunities created by cheaper Southern labour. This result is also counter to Corollary 1 in Cheng et. al. (2005, p. 486), which states that as $\lambda$ increases technology transfer becomes more likely although this is under the condition that the factors engaged in the transmission of technology are supplied at a fixed price.

As the Southern labour force expands the opportunity cost of the resources used in technology transfer, measured by North's relative wage, rise increasing the cost of producing goods using technology transfer, and encouraging production of final goods in the South using Southern labour and technology. Thus, for technology transfer to occur the relative labour supply must lie within the 'Goldilocks' region, $\lambda \in\left(\lambda_{L}, \lambda_{H}\right)$. When the relative labour supply is too high or too low technology transfer will not take place.

\subsection{Improvement in Technology Transfer}

Proposition 1 When technology transfer is incipient a reduction in the costs of technology transfer (a fall in $\varepsilon$ or $\gamma$ ) leads to technology transfer.

Proof. The proof is in the Appendix.

Corollary 1 When $\gamma \in(0, \bar{\gamma})$ and $\varepsilon \in\left(0, \varepsilon^{*}(\gamma)\right)$, and $\lambda \in\left[\lambda_{L}(\varepsilon, \gamma), \lambda_{M}(\varepsilon, \gamma)\right]$, a reduction in the absorption costs, $\varepsilon$, leads to an increase in technology transfer.

Proof. The proof is in the Appendix.

The effect on the relative wage of a fall in transmission or absorption costs is ambiguous. In the remainder of this section we normalize the absorption and transmission shocks so that they have equal measure in terms of the numeraire, and therefore cause the same initial shock. This allows us to make a comparison of impact on the term of trade of an absorption shock relative to a transmission shock. Since $b(j)=1+\varepsilon+w \gamma+w \tilde{a}_{T}(j)$ then a given change in $\gamma$ will cause a 
bigger vertical shift in the $b(j)$ schedule than an identical change in $\varepsilon$ because $w>1$ in equilibrium. Setting $d \varepsilon=w d \gamma_{\varepsilon}$ ensures that the shocks shift the $b(j)$ schedule vertically by the same distance. We begin by demonstrating the effect on the relative wage of a fall in absorption costs. From (11) it follows that

$$
\frac{d w}{d \varepsilon}=\frac{\lambda h_{T T \varepsilon}(w, \varepsilon, \gamma)}{1-\lambda h_{w}(w, \varepsilon, \gamma)} \text { for } \lambda \in\left(\lambda_{L}(\varepsilon, \gamma), \lambda_{H}(\varepsilon, \gamma)\right)
$$

From (10) the effect on the relative wage depends on the impact of a change in $\varepsilon$ on the South's share of world income, with sign $|d w / d \varepsilon|=-\operatorname{sign}\left|z_{1 \varepsilon}-\Theta_{\varepsilon}\right|$ where

$$
z_{1 \varepsilon}-\Theta_{\varepsilon}=\left(1-\theta\left(z_{1}\right)\right) z_{1 \varepsilon}+\theta\left(z_{0}\right) z_{0 \varepsilon}+\int_{z_{0}}^{z_{1}} \frac{\theta(j)}{b(j)} d j
$$

For a fall in absorption costs the South's extensive margin, $z_{0}$, falls and goods initially produced entirely in the South shift to the technology transfer sector reducing the South's share of world income by $\theta\left(z_{0}\right) z_{0 \varepsilon}$, which is represented by area $t$ in Figure 7 .

\section{[Figure 7 about here]}

The North's extensive margin also contracts ( $z_{1}$ rises) and goods that were initially produced entirely in the North shift into the technology transfer sector, to be produced by both the North and the South. This increases the South's share of world income by $-\left(1-\theta\left(z_{1}\right)\right) z_{1 \varepsilon}>0$ (area $q$ and first term in (13)). The fall in $\varepsilon$ reduces the South's intensive margin in the technology transfer sector reducing the South's share of world income (third term in (13), area $r$ ). Whether the South's share of income, and the relative demand for Southern labour, rises or falls as $\varepsilon$ falls depends on the sum of these terms in (13).

When transmission costs fall by $d \gamma_{\varepsilon}$ the effects on the extensive margins are identical however the South's intensive margin expands, represented by area $x$, which increases $z_{1}-\Theta$ and also increase the demand for Southern labour. In this case the effect on the South's share of world income is measured by ${ }^{16}$

$$
z_{1 \gamma_{\varepsilon}}-\Theta_{\gamma_{\varepsilon}}=z_{1 \varepsilon}-\Theta_{\varepsilon}-w \int_{z_{0}}^{z_{1}} \frac{1}{b(j)}
$$

It follows that a fall in transmission costs reduces the relative demand for Northern labour more, or increases it less, than a fall in the absorption cost, as the next result states.

Corollary 2 Comparing the impact on the relative wage of a fall in transmission costs relative to

\footnotetext{
${ }^{16}$ Since the shocks are normalized $\left(w d \gamma_{\varepsilon}=d \varepsilon\right)$ then $z_{0 \gamma_{\varepsilon}}=z_{0 \varepsilon}$, and $z_{0 \gamma_{\varepsilon}}=z_{1 \varepsilon}$.
} 
a fall in absorption costs, it is the case that $d w / d \gamma_{\varepsilon}>d w / d \varepsilon$, where

$$
\frac{d w}{d \gamma_{\varepsilon}}=\frac{d w}{d \varepsilon}-\frac{1}{\Delta} \frac{\lambda}{\left(z_{1}-\Theta\right)^{2}} \frac{1}{z_{0 \varepsilon}} \frac{1}{z_{1 \varepsilon}}\left(\int_{z_{0}}^{z_{1}} \frac{1}{b(j)} d j\right)
$$

Proof. The proof is in the Appendix.

When the shocks are normalized the initial impact on the extensive margins is the same while the effects on the intensive margins differ. A fall in absorption costs reduces the South's intensive margin while a fall in transmission costs expands it. Hence a fall in transmission costs leads to a smaller rise, or a larger fall, in $w$ than a fall in absorption costs which has the same initial impact.

Corollary 3 When technology transfer is incipient an improvement in absorption [lower $\varepsilon$ ], or a fall in transmission costs [lower $\gamma$ ], will lead to an increase (decrease) in $w$ if

$$
\frac{z_{1 \varepsilon}}{z_{0 \varepsilon}}<(>)-\frac{\theta(z)}{(1-\theta(z))}
$$

Proof. The proof is in the Appendix.

In this case there is no adjustment on the intensive margin because initially $z_{0}=z_{1}$. For a fall in $\varepsilon$, or a fall in $\gamma$ where $d \varepsilon=w d \gamma_{\varepsilon}$, the South's extensive margin contracts and goods shift out of the South's final goods sector and into the technology transfer sector, which reduces the the South's share of world income by $\theta(z) z_{0 \varepsilon}$. Similarly the North's extensive margin contracts which increases the South's share of world income by $-(1-\theta(z)) z_{1 \varepsilon}$. Thus, whether the relative demand for Southern labour rises or falls depends on $-(1-\theta(z)) z_{1 \varepsilon}-\theta(z) z_{0 \varepsilon} \gtrless 0$.

Corollary 4 When $d \varepsilon=w d \gamma_{\varepsilon}$, the effects of fall in absorption or transmission costs on Northern and Southern welfare are as follows

$$
\begin{aligned}
\frac{d W^{N}}{d \zeta} & =\left(z_{1}-\Theta\right) \frac{d \ln w_{T}}{d \zeta}-\int_{z_{0}}^{z_{1}} \frac{1}{b(j)} d j \text { for } \zeta=\varepsilon, \gamma_{\varepsilon} \\
\frac{d W^{S}}{d \zeta} & =-\left(1-\left(z_{1}-\Theta\right)\right) \frac{d \ln w_{T}}{d \zeta}-\int_{z_{0}}^{z_{1}} \frac{1}{b(j)} d j \text { for } \zeta=\varepsilon, \gamma_{\varepsilon}
\end{aligned}
$$

where $W^{i}$ is the utility per capita in country $i$.

Proof. The proof is in the Appendix.

The first term in the expressions above is the terms of trade effect which is the percentage change in the terms of trade weighted by the import share. These are opposed between the North 
and South. The second term, which is defined as the efficiency effect, represents the fall in prices of goods produced in the technology transfer sector as transfer becomes more efficient, either because of a fall in $\varepsilon$ or $\gamma$. It is possible that a fall in transfer costs will make both countries better off. From Corollary 2, the North will be relatively better off from a fall in absorptions costs than from a fall in transmission costs.

Since $\ln P_{T}=-\ln W_{T}^{S}$ then the effect on the price level of a change in absorption or transmission costs is given by the negative of (15). The interpretation is the same as that given above. For example, when $d \ln w_{T} / d \zeta<0$ then a fall in $\varepsilon$ or $\gamma$ leads to opposing effects on the price level. The prices of goods produced in the North, and of Northern inputs into the technology transfer, rise putting upward pressure on the price level, and more efficient technology transfer puts downward pressure on the price level.

\subsection{Productivity Shocks}

Proposition 2 (Southern catch-up) When there is technology transfer $\left(z_{1}-z_{0}>0\right)$, a proportional catch-up in the productivity of the Southern final goods sector leads to an increase in the South's relative wage. In addition, when $\lambda \leqslant \lambda_{m}$, or when $\lambda>\lambda_{m}$ and $z_{0 w}-z_{1 w}<\left(z_{1}-\Theta\right)^{2} / \theta\left(z_{0}\right) \lambda$, it leads to a contraction in technology transfer.

Proof. The proof is in the Appendix.

A proportional Southern productivity improvement shifts the $z_{0}($.$) locus upward, as may be$ visualized in Figure 2. The impact of this at the initial wage is to reduce the size of the technology transfer sector. Since the productivity improvement causes $w$ to fall then when $w \leqslant w_{m}\left(\lambda \leqslant \lambda_{m}\right)$ it follows that $z_{1}-z_{0}$ is reduced further. However, when $w>w_{m}\left(\lambda>\lambda_{m}\right)$ if $z_{0 w}-z_{1 w}$ is large then the range of goods produced in the technology transfer sector may rise as $w$ falls. The condition above places a restriction on the magnitude of $z_{0 w}-z_{1 w}$ to ensure the result.

The intuition of this result is as follows. A proportional productivity catch-up means that the $a(j)$ schedule rotates downward around the vertical intercept $a(0)=1$ as the productivity of Southern final goods producers improves in proportion to their distance from the Northern benchmark of unity, as in Figure 8. The productivity of Southern firms producing good 0, who are as productive as their Northern counterparts, doesn't change. This is modeled as a fall in South's productivity parameter, $\rho^{S}$, (from an initially value of unity) where the condition determining the South's extensive margin $z_{0}$ is $1+\rho^{S}\left(a\left(z_{0}\right)-1\right)=e+w a_{T}\left(z_{0}\right)$. This shifts $z_{0}$ to the right at the 
initial wage because production costs fall in that sector increasing the relative demand for Southern labour. This pushes down the North's relative wage shifting the $b(j)$ schedule down, decreasing $z_{1}$ and expanding Northern final goods production. The movement between the initial and final equilibria are demonstrated in Figure 8, with the final equilibrium given by $\left(w_{T}^{*}, z_{0}^{* *}, z_{1}^{*}\right)$.

[Figure 8 about here]

Corollary 5 The effects of a proportional catch-up in the productivity of the South's final goods sector on Northern and Southern welfare are as follows:

$$
\begin{aligned}
\frac{d W_{T}^{N}}{d \rho^{S}} & =z_{1} \frac{d \ln w_{T}}{d \rho^{S}}-\left(\frac{z_{0}}{\rho^{S}}-\frac{1}{\rho^{S}} \int_{0}^{z_{0}} \frac{1}{1+\rho^{S}(a(j)-1)} d j\right) \gtreqless 0 \\
\frac{d W_{T}^{S}}{d \rho^{S}} & =-\left(1-z_{1}\right) \frac{d \ln w_{T}}{d \rho^{S}}-\left(\frac{z_{0}}{\rho^{S}}-\frac{1}{\rho^{S}} \int_{0}^{z_{0}} \frac{1}{1+\rho^{S}(a(j)-1)} d j\right)<0
\end{aligned}
$$

Proof. The proof is in the Appendix.

The first term in the expressions (16) and (17) are the terms of trade effects, which are opposed. The second term in both expressions is the efficiency effect and represent the fall in prices of goods produced in the South due to the improved productivity. From (48), $d \ln w_{T} / d \rho^{S}>0$ and the terms of trade move in favour of the South. An improvement in Southern final goods technology leaves the South better off and the effect on Northern welfare, where the terms of trade and efficiency effects oppose, is ambiguous.

If the South continues to experience a proportional technological catch-up, eventually technology transfer is extinguished, and the DFS equilibrium results. ${ }^{17}$ In the limit if the proportional catchup continues, then $\rho^{S}$ approaches zero and the South's technology approaches that of the North in all goods $(a(j)$ approaches unity for all goods $j)$, and the equilibrium approaches autarky.

Proposition 3 (North leaps ahead) When there is technology transfer $\left(z_{1}-z_{0}>0\right)$, a uniform improvement in the productivity of the Northern final goods sector leads to an increase in the North's relative wage. In addition, when $\lambda \geqslant \lambda_{m}$, or when $\lambda<\lambda_{m}$ and $z_{1 w}-z_{0 w}<\left(z_{1}-\Theta\right)^{2} /\left(1-\theta\left(z_{1}\right)\right) \lambda$, it leads to a contraction in technology transfer.

Proof. The proof is in the Appendix.

\footnotetext{
${ }^{17}$ Note that from (44), the vertical intercept of the $z_{0}($.$) locus is determined by z_{0}=a^{-1}\left(\left(\varepsilon+\rho^{S}\right) / \rho^{S}\right)$. As $\rho^{S}$ falls then the $z_{0}($.$) locus shifts upward.$
} 
A uniform productivity improvement in the North shifts the $z_{1}($.$) locus downwards. This is$ represented by a fall in $\rho^{N}$, the productivity in the North's final good sector, from an initial value of unity. ${ }^{18}$ At the initial wage this reduces the size of the technology transfer sector. Because the wage rises then for $w \geqslant w_{m}\left(\lambda \geqslant \lambda_{m}\right)$ the technology transfer sector contracts further. However for $\lambda<\lambda_{m}$ the effect of the increase in $w$ acts counter to initial impact on the size of the technology transfer sector because $z_{1 w}>z_{0 w}$, and a restriction must be placed on the size of $z_{1 w}-z_{0 w}$ to ensure the result.

A uniform productivity improvement in Northern final goods sector shifts the $z_{1}$ margin to the left at the initial wage because production costs fall in that sector. This increases the relative demand for Northern labour as goods produced originally in the technology transfer sector on that margin release Southern labour and are now produced only in the North. This bids up the relative wage, and $z_{0}$ increases and $z_{1}$ decreases. The movement between the initial and final equilibria are demonstrated in Figure 9 (with post-shock variables indicated by an *).

[Figure 9 about here]

Corollary 6 The effect of a uniform improvement in the productivity of the North's final goods sector on Northern and Southern welfare is as follows:

$$
\begin{aligned}
\frac{d W^{N}}{d \rho^{N}} & =z_{1} \frac{d \ln w_{T}}{d \rho^{N}}-\frac{\left(1-z_{1}\right)}{\rho^{N}}>0 \\
\frac{d W^{S}}{d \rho^{N}} & =-\left(1-z_{1}\right) \frac{d \ln w_{T}}{d \rho^{N}}-\frac{\left(1-z_{1}\right)}{\rho^{N}} \gtreqless 0
\end{aligned}
$$

Proof. The proof is in the Appendix.

The interpretation of (18) and (19) is similar to the case above, except that the efficiency effect is now over the range of goods $\left[z_{1}, 1\right]$, as opposed to $\left[0, z_{0}\right)$ in the previous case. From (61) the terms of trade move in favour of the North, and the North is always better off while the effect on Southern welfare is ambiguous.

\section{$5 \quad$ Welfare and Prices}

In this section we examine the impact on prices and welfare of the movement between the free trade (DFS) and technology transfer equilibria.

\footnotetext{
${ }^{18}$ The North's extensive margin, $z_{1}$, is determined by $\rho^{N} w=e+w a_{T}\left(z_{1}\right)$.
} 


\subsection{Global Welfare}

Lemma 6 Technology transfer leads to an increase in world real income, which is determined by ${ }^{19}$

$$
\ln \left(\frac{Y_{T}}{P_{T}}\right)-\ln \left(\frac{Y_{D}}{P_{D}}\right) \approx \int_{z_{0}}^{z_{D}}(\ln a(j)-\ln b(j)) d j+\int_{z_{D}}^{z_{1}}\left(\ln w_{T}-\ln b(j)\right) d j>0
$$

where $Y_{i} / P_{i}$ is world income deflated by the price index $P_{i}$, for $i=T, D$.

Proof. The proof is in the Appendix.

In the movement from the free trade to the technology transfer equilibrium world welfare increases. From a world perspective the terms of trade effects between countries are internalized. The two terms on the RHS represent the efficiency gains due to the transfer of technology from North to South: the first term because of the transfer of technology to Southern incumbent producers on $\left[z_{0}, z_{D}\right)$, and the second term because technology transfer which has stimulated Southern entry into goods on $\left[z_{D}, z_{1}\right)$. Both terms are positive since $a(j)>b(j)$ on $\left[z_{0}, z_{D}\right)$ and $w_{T}>b(j)$ on $\left[z_{D}, z_{1}\right)$.

\subsection{Welfare in the North and South}

The change in welfare per capita in the North is

$$
\Delta W_{T-D}^{N}=z_{D} \ln \frac{w_{T}}{w_{D}}+\int_{z_{0}}^{z_{D}}(\ln a(j)-\ln b(j)) d j+\int_{z_{D}}^{z_{1}}\left(\ln w_{T}-\ln b(j)\right) d j
$$

The first term is the terms of trade effect and the second and third terms are the efficiency gains noted above. If the terms of trade were to move very strongly against the North it is possible this loss would outweigh the efficiency gains. Such an adverse movement is unlikely as the fall in demand for Northern labour due to relocating goods is offset by higher demand in the transmission of technology, and it is likely that the North will be better off than under free trade.

If transmission and absorption costs are zero, as in Samuelson (2004), then the South is able to perfectly absorb all Northern technology, and relative (and absolute) labour productivities are equalized at unity for all goods. Comparative advantage is eliminated, and welfare in the North is driven back to its autarkic level. As we demonstrate in the next result, Northern welfare in the technology transfer equilibrium is always above the autarkic level.

\footnotetext{
${ }^{19}$ The subscript $D$ denotes the DFS benchmark (pre-technology transfer situation), and the subscript $T$ denotes the technology transfer situation.
} 
Lemma 7 The North is better off in the technology transfer equilibrium than under autarky, since $e^{20}$

$$
\Delta W_{T-A}^{N}=W_{T}^{N}-W_{A}^{N}=\int_{0}^{z_{0}}\left(\ln w_{T}-\ln a(j)\right) d j-\int_{z_{0}}^{z_{1}}\left(\ln w_{T}-\ln b(j)\right) d j>0
$$

Proof. The proof is in the Appendix.

The resource costs of technology transfer make it uneconomic to transfer technology in all goods, and it will occur only on a fraction of the goods continuum $\left[z_{0}, z_{1}\right)$. For goods above and below this interval relative efficiencies are unchanged. The first term above is the gains due to final goods trade with the South, and the second term is the gains from trade attributed to the technology transfer sector.

If transmission and absorption costs were to fall to zero the South has Northern technology and is in autarky. We show below that the South would be better off in this situation than in the technology transfer equilibrium.

Lemma 8 The South is better off when technology transfer is costless, in which case it has Northern technology and is in autarky, than when technology transfer is costly since

$$
W_{T}^{S}-W_{A^{*}}^{S}=-\left(1-z_{1}\right) \ln w_{T}-\int_{z_{A}}^{z_{0}} \ln a(j) d j-\int_{z_{0}}^{z_{1}} \ln b(j) d j<0
$$

Proof. The proof is in the Appendix.

\subsection{Prices}

The difference between the price level in the post- and pre-technology transfer equilibria is

$$
\ln \frac{P_{T}}{P_{D}}=\left(1-z_{D}\right) \ln \frac{w_{T}}{w_{D}}-\int_{z_{0}}^{z_{D}}(\ln a(j)-\ln b(j)) d j-\int_{z_{D}}^{z_{1}}\left(\ln w_{T}-\ln b(j)\right) d j
$$

The first term represents the change in the prices of goods on $\left[z_{1}, 1\right]$ which depends on the movement of the terms of trade, $w_{T} / w_{D}$, and may be positive or negative. The second and third terms represent the efficiency gains, which will lower prices. The change in the price level between the post- and pre-technology transfer equilibrium is ambiguous. Since $W_{i}^{S}=-\ln P_{i}$ for $i=D, T$, then the change in Southern welfare between the post- and pre-technology transfer equilibrium is $\Delta W_{T-D}^{S}=\ln P_{D} / P_{T}$.

\footnotetext{
${ }^{20}$ The subscript $A$ indicates the autarkic equilibrium.
} 


\subsection{Empirical Evidence on FDI Flows}

To demonstrate the empirical relevance of this model we briefly examine some empirics. Since foreign direct investment (FDI) is a primary channel through which technology transfer takes place we look at FDI flows between developed, and developing and transition, economies over the period 1970 to 2013. We rely on the World Economic Situation and Prospects (WESP) classification of countries into developed, transition, and developing economies. This classification is determined by basic economic conditions, of which gross national income (GNI) per capita is an important determinant. Recalling that labor in this model is a Leontief aggregate, then the wage is a measure of GNI per capita. Examining FDI flows over the period 1970-2013 we find that net outflows as a proportion of total world FDI from developed economies to developing and transition economies averaged $22.8 \%$, while over the same period net inflows as a proportion of total world FDI into transition and developing economies were $20.7 \% .{ }^{21}$ Hence high wage countries are net providers, and low wage countries net recipients, of FDI.

\section{Technology Transfer and Intellectual Property Rights}

In the preceding analysis it is assumed that the blueprints for the Northern technology are freely available and can be accessed at zero cost. The model is modified to examine the case where a licence fee must be paid to use Northern technology. We now interpret $\gamma$ as a licence fee which is charged for each unit of goods produced using Northern technology by both Southern and Northern firms. The licence fee is a rent paid to Northern workers, who are the owners of the advanced technology. While the imposition of a licence fee increases the cost of producing goods using Northern technology, it does not affect the resources required to produce them. There is now a mark-up on goods on $\left[z_{1}, 1\right]$. The cost of producing goods in the Northern final goods sector is now $w(1+\gamma)$ and $(3)$ becomes $w=e+w \tilde{a}_{T}\left(z_{1}\right)$ which is independent of $\gamma$, while (2) is unchanged. The payment to Northern workers for the use of advanced technology is the total volume of goods on $\left[z_{0}, 1\right]$ multiplied by the licence fee $\gamma$. The share of world income paid as licence fees is

$$
\phi=\left(\frac{\left(1-z_{1}\right) \gamma}{(1+\gamma)}+\left(\Theta\left(w, z_{0}, z_{1}\right)-\tilde{\Theta}\left(w, z_{0}, z_{1}\right)\right)\right)
$$

\footnotetext{
${ }^{21}$ Using the UNCTADSTAT Inward and outward foreign direct investment flows, annual, 1970-2013 database we subtract annual inflows from outflows and then divide by annual world FDI. Since annual world FDI inflows and outflows do not match perfectly we take a simple average of them to calculate annual world FDI.
} 
where $\tilde{\Theta}\left(w, z_{0}, z_{1}\right)=\int_{z_{0}}^{z_{1}}\left(w \tilde{a}_{T}(j) / b(j)\right) d j$ is the average factor share of Northern labour in technology transfer while $\Theta\left(w, z_{0}, z_{1}\right)=\int_{z_{0}}^{z_{1}}\left(w\left(\gamma+\tilde{a}_{T}(j)\right) / b(j)\right) d j$ is the average factor share including license fee payments. The first term in (22) represents the share of world income paid as license fees for goods produced in the North's final goods sector, while the second term represents the share for goods produced in the technology transfer sector. Because preferences are homothetic the equilibrium is independent of the distribution of license fee revenue amongst the Northern workforce, however for the purposes of this analysis we assume it to be equally shared. The income of a Northern worker is the wage plus an equal share of the license fee payments, $w+\phi Y / L^{N}$. World income is now ${ }^{22} Y=\left(w L^{N}+L^{S}\right) /(1-\phi)$ and substitution of this into the South's labour market equilibrium condition, $L^{S}=\left(z_{1}-\Theta\right) Y$, leads to an expression for the balance of trade,

$$
w=\frac{1-\phi-\left(z_{1}-\Theta\right)}{\left(z_{1}-\Theta\right)} \lambda
$$

We examine the impact of a shock in which license fees increase by $d \gamma$ due to more effective international enforcement of intellectual property rights, for example because of an agreement such as TRIPS. This shock is examined in the simple linear model, where $a(j)=1+\sigma j$ and $b(j)=\varepsilon+w(\gamma+j / \tau)$. The constant $\sigma$ represents the rate at which relative efficiency of Northern final goods production increases in $j$, while $1 / \tau$ indicates the rate at which transmission costs increase with $j$. Assumptions (A1) and (A2) impose that $\sigma \tau>w$. In addition, property iii. imposes that $\tau \leq 1 /(1-\gamma)$ and so $\tau$ is set to unity for simplicity. The model is

$$
\begin{aligned}
z_{0} & =\frac{\varepsilon+w \gamma}{\sigma-w} \\
z_{1} & =\frac{w-e}{w} \\
w & =\frac{1-\left(1+\frac{\left(1-z_{1}\right) \gamma}{(1+\gamma)}+\gamma \ln v\right)-\left(z_{0}+\frac{e}{w} \ln v\right)}{\left(z_{0}+\frac{e}{w} \ln v\right)} \lambda
\end{aligned}
$$

where $v=\left(e+w \gamma+w z_{1}\right) /\left(e+w \gamma+w z_{0}\right)$. An increase in the license fee increases the price of all goods which use Northern technology. This has no initial impact on the North's extensive margin as the cost of producing goods in the technology transfer and Northern final goods sectors both increase by $w d \gamma$. However, the South's extensive margin, $z_{0}$, expands reducing the demand for Northern labour which leads the North's relative wage to fall. The convergence of wages between

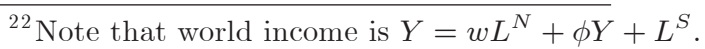


the North and the South because of an improvement in intellectual property rights found here is also present in Gancia and Bonfiglioli (2008). They examine a Ricardian trade model of NorthSouth trade and technological progress where the South has weak IPR. When countries trade and specialize according to comparative advantage, because poor countries do not have adequate IPR, innovative activity is not profitable and there is less R\&D in the South. This causes an increase in the technological gap between the North and South and through this an increase in the North's relative wage. Thus, when IPR in the South improve wages converge.

The size of the fall in the relative wage depends on $\sigma$ which determines the slope of $a(j)$, and therefore responsiveness of $z_{0}$ to the rise in $\gamma$. When $\sigma$ is low, a given rise in $\gamma$ causes a larger increase in $z_{0}$ reducing the relative demand for Northern labour, and thus decreasing the relative wage, by more. If the fall in the relative wage is large enough it is possible that the income of Northern workers may fall. Despite an increase in license fee payments from the South as $\gamma$ rises the worker's total remuneration, $w+\phi Y / L^{N}$, falls because the decrease in the wage is larger. Further, it is also possible that the price level may fall as the reduction in the wage offsets the impact of higher license fees on the prices of goods on $\left[z_{1}, 1\right]$. In this case Southern workers are better off, and the impact on Northern welfare depends on the relative sizes of the falls in income and prices.

Indeed, it is possible to construct such a case and when $\sigma=2$ this is exactly what happens. ${ }^{23}$ An increase in $\gamma$ lowers the North's relative wage, and also the price level, and causes a fall in the income of Northern workers. The welfare of Southern workers increases and, because the fall in income is proportionately higher than the fall in the price level, Northern workers are worse off. When $\sigma=2.5$, the fall in the relative wage is smaller and is not enough to offset the impact of the increase in license fees and the price level rises. While the rise in license fee revenue is enough to offset the lower wage and Northern income goes up, it is not by enough to offset the higher price level, and the welfare of both Southern and Northern workers falls. In a final case, when $\sigma=3$, the fall in the relative wage is smaller still, so that despite the rise in the price level Northern workers are better off, while those in the South are worse off. Thus it is possible, as demonstrated using the simple functional forms above, that better intellectual property rights could make the North worse off, and the South better off.

\footnotetext{
${ }^{23}$ See the Online Appendix for the solutions of the model and the effects on wages, prices and welfare.
} 


\section{Conclusion}

This paper presents a simple general equilibrium framework within which to examine trade and technology transfer when it is costly. Within this framework we examine the impact of a number of different shocks. The move from free trade to the technology transfer equilibrium generates additional efficiency gains and, unless the terms of trade move very strongly against the North, it is better off. Such an adverse movement in the terms of trade is unlikely. Unlike the case of costless technology transfer, where the terms of trade move against the North, the effect of freer technology transfer on the relative wage is ambiguous and indeed it is possible that the North's terms of trade will improve. The fall in the demand for Northern labour as goods (and technology) relocate to the South is offset by an increase in the demand for Northern resources in the transmission of technology. Northern labour is required not only for the transmission of technology of the relocating goods, but also for goods produced by Southern producers who choose to adopt Northern technology. These sources of demand are ignored when technology transfer is assumed to be costless.

This contrasts with Samuelson (2004) which demonstrates a case in which costless technology transfer can drive the welfare of the North to its autarkic level. We show that Northern welfare in the technology transfer equilibrium is always higher than in the autarky equilibrium which results if technology transfer is costless. When the transfer of technology is costly, transfer occurs only in goods in which it is economic to do so. Technology transfer will not take place in the goods in which comparative advantage is strongest: the simplest goods for the South, and the most sophisticated goods for the North. The initial relative efficiencies are maintained in these goods and the transfer of technology in the remaining goods leads to additional efficiency gains.

\section{Appendix}

Lemma 1 The utility per capita is equal to the real wage, where $\ln \left(U^{N} / L^{N}\right)=\ln (w / P)$ and $\ln \left(U^{S} / L^{S}\right)=\ln (1 / P)$, where $\ln P=\int_{0}^{1} \ln p(j) d j$ is the true price index.

Proof. The consumption of good $j$ in country $i$ is

$$
y^{i}(j)=\frac{E^{i}}{p(j)} \text { for } i=N, S
$$


where in equilibrium $E^{N}=w L^{N}$ and $E^{S}=L^{S}$. Substitution of (24) into the utility function gives

$$
\ln U^{i}=\int_{0}^{1} \ln \left(\frac{E^{i}}{p(j)}\right) d j=\ln \left(w^{i} L^{i}\right)-\int_{0}^{1} \ln p(j) d j
$$

Setting the price index $\ln P=\int_{0}^{1} \ln p(j) d j$, which is the true price index, then this expression may be rewritten as above.

Lemma DFS For each value of $\lambda \in(0, \infty)$ there is a unique solution to the DFS-benchmark model denoted by $\left(z_{D}(\lambda), w_{D}(\lambda)\right)$. As $\lambda$ increases the equilibrium wage and cut-off good, $w_{D}$ and $z_{D}$, increase.

Proof. Since $z^{\prime}(w)>0$, and defining the RHS of $(6)$ as $h_{D F S}(w) \lambda$, then $\frac{\partial h_{D F S}(w) \lambda}{\partial w}<0$. The $R H S$ of (6) is decreasing in $w$, while the LHS is increasing in $w$. Also since as $w$ approaches one then $z$ approaches zero and therefore $h_{D F S}(w) \lambda$ approaches infinity, then $h_{D F S}(w) \lambda>w$ for small $w$. This ensures a unique equilibrium, denoted by the pair $\left(z_{D}(\lambda), w_{D}(\lambda)\right)$. Since an increase in $\lambda$ will shift the $h_{D F S}(w) \lambda$ locus outward, then $w_{D}^{\prime}(\lambda)>0$, and it follows that $z_{D}^{\prime}(\lambda)>0$.

Corollary DFS For any given pair $(z(w), w)$ there exists a unique $\lambda$ which ensures an equilibrium in the DFS-benchmark model.

Proof. This follows directly from equation (6).

8.0.1 Properties of $z_{0}(w, \varepsilon, \gamma)$ and $z_{1}(w, \varepsilon, \gamma)$ :

Equations (2) and (3) may be used to determine the responses of $z_{0}$ and $z_{1}$ to changes in $w$ and $\varepsilon$. From (2), then ${ }^{24}$

$$
\begin{aligned}
z_{0 w} & =\frac{a_{T}\left(z_{0}\right)}{a^{\prime}\left(z_{0}\right)-w \tilde{a}_{T}^{\prime}\left(z_{0}\right)}>0 \text { by }(A 1) \\
z_{0 \varepsilon} & =\frac{1}{a^{\prime}\left(z_{0}\right)-w \tilde{a}_{T}^{\prime}\left(z_{0}\right)}>0 \quad \text { by }(A 1) \\
z_{0 \gamma} & =\frac{w}{a^{\prime}\left(z_{0}\right)-w \tilde{a}_{T}^{\prime}\left(z_{0}\right)}=w z_{0 \varepsilon}>0 \text { by }(A 1)
\end{aligned}
$$

Differentiating $z_{0 w}$ with respect to $w$ gives $^{25}$

\footnotetext{
${ }^{24}$ Note that by the Implicit Function Theorem $\left.\frac{d z_{i}}{d w}\right|_{d \varepsilon, d \gamma=0}=\frac{\partial z_{i}}{\partial w}=z_{i w},\left.\frac{d z_{i}}{d \varepsilon}\right|_{d w, d \gamma=0}=\frac{\partial z_{i}}{\partial \varepsilon}=z_{i \varepsilon}$ and $\left.\frac{d z_{i}}{d \gamma}\right|_{d w, d \varepsilon=0}=$ $\frac{\partial z_{i}}{\partial \gamma}=z_{i \gamma}$ for $i=0,1$.

${ }^{\partial 2} A 2$ may be assured by assuming that $a^{\prime \prime}\left(z_{0}\right) \leqslant w L_{T}^{\prime \prime}\left(z_{0}\right)$
} 


$$
z_{0 w w}=\frac{\partial z_{0 w}}{\partial w}=a_{T}\left(z_{0}\right)\left(2 a_{T}^{\prime}\left(z_{0}\right)-z_{0 w}\left(a^{\prime \prime}\left(z_{0}\right)-w a_{T}^{\prime \prime}\left(z_{0}\right)\right)\right) \geqslant 0 \text { by }(A 2)
$$

which may be assured by assuming that $a^{\prime \prime}\left(z_{0}\right) \leqslant w L_{T}^{\prime \prime}\left(z_{0}\right)$. Using (3) allows calculation of

$$
\begin{aligned}
z_{1 w} & =\frac{1-a_{T}\left(z_{1}\right)}{w \tilde{a}_{T}^{\prime}\left(z_{1}\right)}>0 \\
z_{1 \varepsilon} & =-\frac{1}{w \tilde{a}_{T}^{\prime}\left(z_{1}\right)}<0 \\
z_{1 \gamma} & =-\frac{1}{\tilde{a}_{T}^{\prime}\left(z_{1}\right)}=w z_{1 \varepsilon}<0
\end{aligned}
$$

Note the $z_{1 w}>0$ since $a_{T}\left(z_{1}\right)<1$ from (3). Differentiating $z_{1 w}$ with respect to $w$ gives

$$
z_{1 w w}=\frac{z_{1 w}}{w}\left(e z_{1 \varepsilon} \frac{\tilde{a}_{T}^{\prime \prime}\left(z_{1}\right)}{\tilde{a}_{T}^{\prime}\left(z_{1}\right)}-2\right)<0
$$

Shape of loci For the $z_{0}(w, \varepsilon, \gamma)$ locus, from $(2)$, since $w a_{T}\left(z_{0}\right)=a\left(z_{0}\right)-e$, then when $w=0$ it follows that $a\left(z_{0}\right)=e$, and the $z$-intercept is $z_{0}=a^{-1}(e)$. Further, by (A2), $z_{0 w w} \geqslant 0$, then $z_{0}(w, e)$ is increasing at a non-decreasing rate from the intercept $a^{-1}(e)$. For the $z_{1}(w, \varepsilon, \gamma)$ locus from $(3), 1-\gamma-e / w=\tilde{a}_{T}\left(z_{1}\right)$ and at $w=e /(1+\gamma)$ then $\tilde{a}_{T}\left(z_{1}\right)=0$ and $z_{1}=0$ by property ii. Since $z_{1 w w}<0$, then as $w$ increases $z_{1}$ is increasing at a decreasing rate. Further, as $w$ rises $\tilde{a}_{T}\left(z_{1}\right)$ approaches $1-\gamma$ from below. By property iii. $\tilde{a}_{T}(1) \geqslant 1-\gamma$ which ensures that $z_{1}<1$.

Lemma 2 When $\varepsilon=0$ the value of $\gamma$ which ensures tangency between $z_{0}(w, \varepsilon, \gamma)$ and $z_{1}(w, \varepsilon, \gamma)$ is $\bar{\gamma}$. For $\gamma<\bar{\gamma}$ there exists a value of $\varepsilon>0$, defined as $\varepsilon^{*}(\gamma)$ at which there is tangency between $z_{0}($.$) and z_{1}($.$) .$

Proof. When $\varepsilon=\gamma=0$, the $z_{0}(w, 0,0)$ and $z_{1}(w, 0,0)$ loci intersect at two points, defined $z_{L}$ and $z_{H}$. The first intersection point is at $z_{L}=0$, since at $\gamma=\varepsilon=0$ when $w=1$ then $z_{0}=z_{1}=0$. Since at this point $z_{1 w}(1,0,0)=1 / \tilde{a}_{T}^{\prime}(0) \geqslant z_{0 w}(1,0,0)=0$ and also that $z_{0 w w} \geq 0$ and $z_{1 w w}<0$ there is another intersection point in the positive quadrant. By property iii., which ensures that $z_{1}<1$, the second point of intersection must be such that $z_{H}<1$. Increasing $\gamma$ from zero rotates the $z_{0}$ (.) locus upwards and shifts the $z_{1}($.$) locus to the right. Since z_{0 w w} \geqslant 0$ and $z_{1 w w}<0$ there is a $\gamma>0$, defined as $\bar{\gamma}$, at which there is a unique point of tangency between the loci. Decreasing $\gamma$ below $\bar{\gamma}$ means that the loci will again intersect at two points, and so $\varepsilon$ may be increased until 
there is a tangency once again at $\varepsilon^{*}(\gamma)>0$.

Lemma 3 When $\gamma \geq \bar{\gamma}$, or $\varepsilon \geq \varepsilon^{*}(\gamma)$, there is no technology transfer, and the solution to the model is given by the DFS benchmark.

Proof. Given the definitions of $\bar{\gamma}$ and $\varepsilon^{*}(\gamma)$, then in either of these cases $z_{0}($.$) and z_{1}($.$) are$ either tangent or non-touching. Equations (2) and (3) reduce to $w=a(z)$ and (7) becomes $w=((1-z) / z) L^{S} / L^{N}$, and the model reduces to the DFS benchmark, with equations (4) and $(5)$, and solution $\left(z_{D}(\lambda), w_{D}(\lambda)\right)$.

Lemma 4 When $\gamma \in[0, \bar{\gamma})$ and $\varepsilon \in\left[0, \varepsilon^{*}(\gamma)\right)$ there are two points of intersection between $z_{0}(w, \varepsilon, \gamma)$ and $z_{1}(w, \varepsilon, \gamma)$ on $[0,1)$, which are defined $\left(z_{L}\left(w_{L}\right), w_{L}\right)$ and $\left(z_{H}\left(w_{H}\right), w_{H}\right)$. Associated with each point of intersection is a relative labour endowment, $\lambda_{L}(\varepsilon, \gamma)$ and $\lambda_{H}(\varepsilon, \gamma)$ respectively. Conditions for technology transfer require that $\gamma \in[0, \bar{\gamma}), \varepsilon \in\left[0, \varepsilon^{*}(\gamma)\right)$ and $\lambda \in\left(\lambda_{L}(\varepsilon, \gamma), \lambda_{H}(\varepsilon, \gamma)\right)$.

Proof. From Lemma 2, given the properties of $z_{0}(w, \varepsilon, \gamma)$ and $z_{1}(w, \varepsilon, \gamma)$ there are two points of intersection between the these loci when $\gamma \in[0, \bar{\gamma})$ and $\varepsilon \in\left[0, \varepsilon^{*}(\gamma)\right)$. At points of intersection, $z_{0}(w, \varepsilon, \gamma)=z_{1}(w, \varepsilon, \gamma)=z_{i}, i=L, H$, and equations (2) and (3) reduce to $w=a\left(z_{i}\right)$. From Corollary 1, corresponding to $\left(z_{L}\left(w_{L}\right), w_{L}\right)$ and $\left(z_{H}\left(w_{H}\right), w_{H}\right)$ are $\lambda_{L}(\varepsilon, \gamma)$ and $\lambda_{H}(\varepsilon, \gamma)$ respectively, which solve (6) for each case. When $\lambda \leq \lambda_{L}(\varepsilon, \gamma), \lambda_{H}(\varepsilon, \gamma)$ or $\lambda \geqslant \lambda_{H}(\varepsilon, \gamma)$ then $z_{1} \leq z_{0}$ and technology transfer is ruled out. Hence for technology transfer to occur requires $\lambda \in\left(\lambda_{L}(\varepsilon, \gamma), \lambda_{H}(\varepsilon, \gamma)\right)$.

\subsection{Shocks}

\subsubsection{Population Shock}

Lemma 5 When $\varepsilon \in\left[0, \varepsilon^{*}(\gamma)\right)$ and $\lambda \in\left(\lambda_{L}(\varepsilon, \gamma), \lambda_{H}(\varepsilon, \gamma)\right)$ there exists a relative labour endowment $\lambda_{m}$ and a corresponding equilibrium $\left(z_{0}^{m}, z_{1}^{m}, w_{m}\right)$ at which technology transfer is maximized.

Proof. Since expenditure shares are equal and constant for all goods, resources in technology transfer are maximized when $z_{1}-z_{0}$ is maximized. The functions $z_{1}(w, \varepsilon, \gamma)$ and $z_{0}(w, \varepsilon, \gamma)$ are both twice continuously differentiable, and intersect at $w_{L}$ and $w_{H}$ where $w_{L}<w_{H}$, with $z_{0 w w}(w, \varepsilon, \gamma) \geqslant 0 \forall w$ and $z_{1 w w}(w, \varepsilon, \gamma)<0 \forall w$. Since at $w_{L}$ it is the case that $z_{0 w}\left(w_{L}, \varepsilon, \gamma\right)<$ 
$z_{1 w}\left(w_{L}, \varepsilon, \gamma\right)$ and at $w_{H}$ it is the case that $z_{0 w}\left(w_{H}, \varepsilon, \gamma\right)>z_{1 w}\left(w_{H}, \varepsilon, \gamma\right)$, then there exists a wage $w_{m}$ on $\left(w_{L}, w_{H}\right)$ defined by

$$
\frac{d\left(z_{1}-z_{0}\right)}{d w}=0 \Leftrightarrow z_{0 w}\left(w_{m}, \varepsilon, \gamma\right)=z_{1 w}\left(w_{m}, \varepsilon, \gamma\right)
$$

at which $z_{1}-z_{0}$ is maximized. Given (11) then $\lambda_{m}$ is determined by $w_{m}=h\left(w_{m}, \varepsilon, \gamma\right) \lambda_{m}$. An increase in $\lambda$ from $\lambda_{m}$ leads to an increase in $w$ and a fall in $z_{1}-z_{0}$ as $z_{0 w}(w, \varepsilon, \gamma)>z_{1 w}(w, \varepsilon, \gamma)$ for $w>w_{m}$. A decrease in $\lambda$ from $\lambda_{m}$ leads to a fall in $w$ and a fall in $z_{1}-z_{0}$ as $z_{0 w}(w, \varepsilon, \gamma)<$ $z_{1 w}(w, \varepsilon, \gamma)$ for $w<w_{m}$.

\subsubsection{Improvement in Technology Transfer}

We examine both a fall in absorption costs, $\varepsilon$, and a fall in transmission costs, $\gamma$. When there is a change in $\varepsilon$ the system of equations becomes

$$
\begin{aligned}
& {\left[\begin{array}{ccc}
\left(1-\frac{\lambda}{v^{2}} \frac{e}{w} \int_{z_{0}}^{z_{1}} \frac{\theta(j)}{b(j)} d j\right) & \frac{\lambda}{v^{2}} \theta\left(z_{0}\right) & \frac{\lambda}{v^{2}}\left(1-\theta\left(z_{1}\right)\right) \\
\frac{z_{0 w}}{z_{0 \varepsilon}} & -\frac{1}{z_{0 \varepsilon}} & 0 \\
-\frac{z_{1 w}}{z_{1 \varepsilon}} & 0 & \frac{1}{z_{1 \varepsilon}}
\end{array}\right]\left[\begin{array}{c}
d w \\
d z_{0} \\
d z_{1}
\end{array}\right] } \\
= & {\left[\begin{array}{c}
-\frac{\lambda}{v^{2}} \int_{z_{0}}^{z_{1}} \frac{\theta(j)}{b(j)} d j \\
-1 \\
1
\end{array}\right] d \varepsilon }
\end{aligned}
$$

The determinant is

$$
\Delta=-\frac{1}{z_{0 \varepsilon}} \frac{1}{z_{1 \varepsilon}}\left(1+\frac{\lambda}{v^{2}}\left(\left(1-\theta\left(z_{1}\right)\right) z_{1 w}+\theta\left(z_{0}\right) z_{0 w}-\frac{e}{w} \int_{z_{0}}^{z_{1}} \frac{\theta(j)}{b(j)} d j\right)\right)>0 \text { by (A3) }
$$

It follows that

$$
\begin{aligned}
\frac{d w}{d \varepsilon} & =\frac{1}{\Delta} \frac{\lambda}{v^{2}} \frac{1}{z_{0 \varepsilon}} \frac{1}{z_{1 \varepsilon}}\left(\left(1-\theta\left(z_{1}\right)\right) z_{1 \varepsilon}+\theta\left(z_{0}\right) z_{0 \varepsilon}+\int_{z_{0}}^{z_{1}} \frac{\theta(j)}{b(j)} d j\right) \gtrless 0 \\
\frac{d z_{0}}{d \varepsilon} & =\frac{1}{\Delta}\left(-\frac{1}{z_{1 \varepsilon}}+\frac{\lambda}{v^{2}}\left(\left(1-\theta\left(z_{1}\right)\right)+\frac{1}{z_{1 \varepsilon}} \int_{z_{0}}^{z_{1}} \frac{\theta(j)}{b(j)} d j\right)\left(\frac{z_{0 w}}{z_{0 \varepsilon}}-\frac{z_{1 w}}{z_{1 \varepsilon}}\right)\right) \gtrless 0 \\
\frac{d z_{1}}{d \varepsilon} & =\frac{1}{\Delta}\left(-\frac{1}{z_{0 \varepsilon}}-\frac{\lambda}{v^{2}} \theta\left(z_{0}\right)\left(\frac{z_{0 w}}{z_{0 \varepsilon}}-\frac{z_{1 w}}{z_{1 \varepsilon}}\right)\right)<0 \\
\frac{d z_{1}}{d \varepsilon}-\frac{d z_{0}}{d \varepsilon} & =\frac{1}{\Delta}\left(-\frac{\lambda}{v^{2}}\left(\frac{z_{0 w}}{z_{0 \varepsilon}}-\frac{z_{1 w}}{z_{1 \varepsilon}}\right) \frac{1}{z_{1 w}}\left(\left(1-\theta\left(z_{1}\right)\right) z_{1 w}+\theta\left(z_{0}\right) z_{1 w}-\frac{e}{w}\left(\int_{z_{0}}^{z_{1}} \frac{\theta(j)}{b(j)} d j\right)\right)\right.
\end{aligned}
$$


When there is a fall $\gamma$ the system of equations is

$$
\begin{aligned}
& {\left[\begin{array}{ccc}
\left(1-\frac{\lambda}{v^{2}} \frac{e}{w} \int_{z_{0}}^{z_{1}} \frac{\theta(j)}{b(j)} d j\right) & \frac{\lambda}{v^{2}} \theta\left(z_{0}\right) & \frac{\lambda}{v^{2}}\left(1-\theta\left(z_{1}\right)\right) \\
\frac{z_{0 w}}{z_{0 \varepsilon}} & -\frac{1}{z_{0 \varepsilon}} & 0 \\
-\frac{z_{1 w}}{z_{1 \varepsilon}} & 0 & \frac{1}{z_{1 \varepsilon}}
\end{array}\right]\left[\begin{array}{c}
d w \\
d z_{0} \\
d z_{1}
\end{array}\right] } \\
= & {\left[\begin{array}{c}
\frac{\lambda}{v^{2}} e w \int_{z_{0}}^{z_{1}} \frac{1}{(b(j))^{2}} d j \\
-w \\
w
\end{array}\right] d \gamma }
\end{aligned}
$$

and

$$
\begin{aligned}
& \frac{d w}{d \gamma}=\frac{w}{\Delta} \frac{\lambda}{v^{2}} \frac{1}{z_{0 \varepsilon}} \frac{1}{z_{1 \varepsilon}}\left(\left(1-\theta\left(z_{1}\right)\right) z_{1 \varepsilon}+\theta\left(z_{0}\right) z_{0 \varepsilon}-\int_{z_{0}}^{z_{1}} \frac{1-\theta(j)}{b(j)} d j\right) \\
& \frac{d z_{0}}{d \gamma}=-\frac{1}{\Delta}\left(\begin{array}{c}
\frac{w}{z_{1 \varepsilon}}+w \frac{\lambda}{v^{2}} \frac{1}{z_{1 \varepsilon}} \frac{z_{0 w}}{z_{0 \varepsilon}} \int_{z_{0}}^{z_{1}} \frac{1}{b(j)} d j \\
-\frac{\lambda}{v^{2}} w\left(\frac{z_{0 w}}{z_{0 \varepsilon}}-\frac{z_{1 w}}{z_{1 \varepsilon}}\right)\left(1-\theta\left(z_{1}\right)+\frac{1}{z_{1 \varepsilon}} \int_{z_{0}}^{z_{1}} \frac{\theta(j)}{b(j)} d j\right)
\end{array}\right) \\
& \frac{d z_{1}}{d \gamma}=-\frac{1}{\Delta}\left(\frac{w}{z_{0 \varepsilon}}+\frac{\lambda}{v^{2}} \frac{z_{1 w}}{z_{1 \varepsilon}} \frac{w}{z_{0 \varepsilon}} \int_{z_{0}}^{z_{1}} \frac{1}{b(j)} d j+\frac{\lambda}{v^{2}} \theta\left(z_{0}\right) w\left(\frac{z_{0 w}}{z_{0 \varepsilon}}-\frac{z_{1 w}}{z_{1 \varepsilon}}\right)\right) \\
& \left.\frac{d z_{1}}{d \gamma}-\frac{d z_{0}}{d \gamma}=-\frac{1}{\Delta}\left(\begin{array}{c}
+\frac{\lambda}{v^{2}} w\left(z_{1 w}-z_{0 w}\right) \frac{1}{z_{1 w}}\left(\frac{1}{z_{0 \varepsilon}} \frac{w}{z_{1 w}} \int_{z_{1 \varepsilon}}^{z_{1}} \frac{1}{b(j)} d j+\left(\frac{z_{0 w}}{z_{0 \varepsilon}}-\frac{z_{1 w}}{z_{1 \varepsilon}}\right) \theta\left(z_{0}\right)\right) \\
+\frac{\lambda}{v^{2}} w \frac{1}{z_{1 w}}\left(\frac{z_{0 w}}{z_{0 \varepsilon}}-\frac{z_{1 w}}{z_{1 \varepsilon}}\right)\left(\left(1-\theta\left(z_{1}\right)\right) z_{1 w}+\theta\left(z_{0}\right) z_{0 w}-\frac{e}{w} \int_{z_{0}}^{z_{1}} \frac{\theta(j)}{b(j)} d j\right)
\end{array}\right) 39\right)
\end{aligned}
$$

Proposition 1 When technology transfer is incipient a reduction in the costs of technology transfer (a fall in $\varepsilon$ or $\gamma$ ) leads to technology transfer.

Proof. When technology transfers is incipient then setting $z_{0}=z_{1}$ in (35) and (39) leads to

$$
\begin{aligned}
& \frac{d z_{1}}{d \varepsilon}-\frac{d z_{0}}{d \varepsilon}=-\frac{1}{\Delta}\left(\begin{array}{c}
-\frac{1}{z_{0 \varepsilon}}+\frac{1}{z_{1 \varepsilon}} \\
-\frac{\lambda}{v^{2}}\left(\frac{z_{0 w}}{z_{0 \varepsilon}}-\frac{z_{1 w}}{z_{1 \varepsilon}}\right)\left(1-\theta\left(z_{1}\right)+\theta\left(z_{0}\right)\right)
\end{array}\right)<0 \\
& \frac{d z_{1}}{d \gamma}-\frac{d z_{0}}{d \gamma}=-\frac{w}{\Delta}\left(\begin{array}{c}
\frac{1}{z_{0 \varepsilon}}-\frac{1}{z_{1 \varepsilon}} \\
+\frac{\lambda}{v^{2}}\left(\frac{z_{0 w}}{z_{0 \varepsilon}}-\frac{z_{1 w}}{z_{1 \varepsilon}}\right)\left(1-\theta\left(z_{1}\right)+\theta\left(z_{0}\right)\right)
\end{array}\right)<0
\end{aligned}
$$

Corollary 1 When $\gamma \in(0, \bar{\gamma})$ and $\varepsilon \in\left(0, \varepsilon^{*}(\gamma)\right)$, and $\lambda \in\left[\lambda_{L}(\varepsilon, \gamma), \lambda_{M}(\varepsilon, \gamma)\right]$, a reduction in the absorption costs, $\varepsilon$, leads to an increase in technology transfer.

Proof. When $\lambda \in\left[\lambda_{L}(\varepsilon, \gamma), \lambda_{M}(\varepsilon, \gamma)\right]$ then $z_{1 w} \geqslant z_{0 w}$ and from (35) then $d \dot{z}_{1} / d \varepsilon-d z_{0} / d \varepsilon<0$. 
Corollary 2 Comparing the impact on the relative wage of a fall in transmission costs relative to a fall in absorption costs, it is the case that $d w / d \gamma_{\varepsilon}>d w / d \varepsilon$, where

$$
\frac{d w}{d \gamma_{\varepsilon}}=\frac{d w}{d \varepsilon}-\frac{1}{\Delta} \frac{\lambda}{\left(z_{1}-\Theta\right)^{2}} \frac{1}{z_{0 \varepsilon}} \frac{1}{z_{1 \varepsilon}}\left(\int_{z_{0}}^{z_{1}} \frac{1}{b(j)} d j\right)
$$

Proof. From (32) and (36), normalizing the shocks so that $d \varepsilon=w d \gamma_{\varepsilon}$ then this result follows.

Corollary 3 When technology transfer is incipient an improvement in absorption [a fall in $\varepsilon$ ], or a fall in transmission costs [lower $\gamma$ ], will lead to an increase (decrease) in $w$ if $\frac{z_{1 \varepsilon}}{z_{0 \varepsilon}}<(>)-\frac{\theta(z)}{1-\theta(z)}$.

Proof. Since technology transfer is incipient, the relative labour supply is either $\lambda_{L}(\varepsilon, \gamma)$, $\lambda_{H}(\varepsilon, \gamma)$, or $\lambda^{*}\left(\varepsilon^{*}(\gamma), \gamma\right)$, and initially the economy is at $\left(z_{L}, w_{L}\right),\left(z_{H}, w_{H}\right)$, or $\left(z^{*}, w^{*}\right)$. Since $z_{0}=z_{1}(=z)$ then using (11) it can be established that

$$
\frac{d w}{d \varepsilon}=\frac{1}{w} \frac{d w}{d \gamma}=-\frac{(1-\theta(z)) z_{1 \varepsilon}+\theta(z) z_{0 \varepsilon}}{z^{2}+z_{1 w}(1-\theta(z))+\theta(z) z_{0 w}}
$$

and the $\operatorname{sign}|d w / d \varepsilon|=\operatorname{sign}|d w / d \gamma|=-\operatorname{sign}\left|(1-\theta(z)) z_{1 \varepsilon}+\theta(z) z_{0 \varepsilon}\right|$. Rearrangement leads to the condition above.

Corollary 4 When $d \varepsilon=w d \gamma_{\varepsilon}$, the effects of fall in absorption or transmission costs on Northern and Southern welfare are as follows

$$
\begin{aligned}
\frac{d W^{N}}{d \zeta} & =\left(z_{1}-\Theta\right) \frac{d \ln w_{T}}{d \zeta}-\int_{z_{0}}^{z_{1}} \frac{1}{b(j)} d j \text { for } \zeta=\varepsilon, \gamma \\
\frac{d W^{S}}{d \zeta} & =-\left(1-\left(z_{1}-\Theta\right)\right) \frac{d \ln w_{T}}{d \zeta}-\int_{z_{0}}^{z_{1}} \frac{1}{b(j)} d j \text { for } \zeta=\varepsilon, \gamma
\end{aligned}
$$

where $W^{i}$ is the utility per capita in country $i$.

Proof. Applying Lemma 1, when there is technology transfer welfare in the North is

$$
W_{T}^{N}=\ln w_{T}-\int_{0}^{1} \ln p_{T}(j)=z_{1} \ln w_{T}-\int_{0}^{z_{0}} \ln a(j) d j-\int_{z_{0}}^{z_{1}} \ln b(j) d j
$$

and welfare in the South is

$$
W_{T}^{S}=-\int_{0}^{1} \ln p_{T}(j)=-\left(1-z_{1}\right) \ln w_{T}-\int_{0}^{z_{0}} \ln a(j) d j-\int_{z_{0}}^{z_{1}} \ln b(j) d j
$$


Differentiating these expressions with respect to $\varepsilon$ and $\gamma$, where $d \varepsilon=w d \gamma_{\varepsilon}$, leads to the expressions above.

\subsubsection{Productivity Shocks}

Proposition 2 (Southern catch-up) When there is technology transfer $\left(z_{1}-z_{0}>0\right)$, a proportional catch-up in the productivity of the Southern final goods sector leads to an increase in the South's relative wage. In addition, when $\lambda \leqslant \lambda_{m}$, or when $\lambda>\lambda_{m}$ and $z_{0 w}-z_{1 w}<$ $\left(z_{1}-\Theta\right)^{2} / \theta\left(z_{0}\right) \lambda$, it leads to a contraction in technology transfer.

Proof. The system of equations becomes

$$
\begin{aligned}
1+\rho^{S}\left(a\left(z_{0}\right)-1\right) & =e+w a_{T}\left(z_{0}\right) \\
w & =e+w a_{T}\left(z_{1}\right) \\
w & =\left(\frac{1-\left(z_{1}-\Theta\left(w, z_{0}, z_{1}\right)\right)}{z_{1}-\Theta\left(w, z_{0}, z_{1}\right)}\right) \lambda
\end{aligned}
$$

where initially $\rho^{S}=1$. A fall in $\rho^{S}$ means that there is a proportional increase in productivity of Southern firms dependent on their distance from the Northern benchmark, which is unity. Totally differentiating the system of equations leads to

$$
\begin{aligned}
& {\left[\begin{array}{ccc}
\left(1-\frac{\lambda}{v^{2}} \frac{e}{w} \int_{z_{0}}^{z_{1}} \frac{\theta(j)}{b(j)} d j\right) & \frac{\lambda}{v^{2}} \theta\left(z_{0}\right) & \frac{\lambda}{v^{2}}\left(1-\theta\left(z_{1}\right)\right) \\
\frac{z_{0 w}}{z_{0 \varepsilon}} & -\frac{1}{z_{0 \varepsilon}} & 0 \\
-\frac{z_{1 w}}{z_{1 \varepsilon}} & 0 & \frac{1}{z_{1 \varepsilon}}
\end{array}\right]\left[\begin{array}{l}
d w \\
d z_{0} \\
d z_{1}
\end{array}\right] } \\
= & {\left[\begin{array}{c}
0 \\
a\left(z_{0}\right)-1 \\
0
\end{array}\right] d \rho }
\end{aligned}
$$

where initially $\rho^{S}=1$. The determinant is

$$
\Delta=-\frac{1}{z_{0 \varepsilon}} \frac{1}{z_{1 \varepsilon}}\left(1-\frac{\lambda}{v^{2}}\left(\left(1-\theta\left(z_{1}\right)\right) z_{1 w}+\theta\left(z_{0}\right) z_{0 w}+\frac{e}{w} \int_{z_{0}}^{z_{1}} \frac{\theta(j)}{b(j)} d j\right)\right)>0 \text { by (A3) }
$$


Applying Cramer's Rule then

$$
\begin{aligned}
\frac{d w}{d \rho^{S}} & =-\frac{1}{\Delta} \frac{\lambda}{v^{2}} \theta\left(z_{0}\right)\left(a\left(z_{0}\right)-1\right) \frac{1}{z_{1 \varepsilon}}>0 \\
\frac{d z_{0}}{d \rho^{S}} & =\frac{1}{\Delta}\left(\begin{array}{c}
\left(1-\frac{\lambda}{v^{2}} \frac{e}{w} \int_{z_{0}}^{z_{1}} \frac{\theta(j)}{b(j)} d j\right)\left(a\left(z_{0}\right)-1\right) \frac{1}{z_{1 \varepsilon}} \\
+\frac{\lambda}{v^{2}}\left(1-\theta\left(z_{1}\right)\right) \frac{z_{1 w}}{z_{1 \varepsilon}}\left(a\left(z_{0}\right)-1\right)
\end{array}\right) \gtrless 0 \\
\frac{d z_{1}}{d \rho^{S}} & =-\frac{1}{\Delta} \frac{\lambda}{v^{2}} \theta\left(z_{0}\right) \frac{z_{1 w}}{z_{1 \varepsilon}}\left(a\left(z_{0}\right)-1\right)>0 \\
\frac{d z_{1}}{d \rho^{S}}-\frac{d z_{0}}{d \rho^{S}} & =-\frac{1}{z_{1 \varepsilon}}\left(a\left(z_{0}\right)-1\right)\left(1+\frac{\lambda}{v^{2}}\left(z_{1 w}\left(1-\theta\left(z_{1}\right)\right)+z_{1 w} \theta\left(z_{0}\right)-\frac{e}{w} \int_{z_{0}}^{z_{1}} \frac{\theta(j)}{b(j)} d j\right)\right)(51)
\end{aligned}
$$

When $\lambda \leqslant \lambda_{m}$ and so $z_{1 w} \geqslant z_{0 w}$ then from (A3) and (51) it follows that $d\left(z_{1}-z_{0}\right) / d \rho<<$. When $\lambda>\lambda_{m}$ then $z_{0 w}>z_{1 w}$ and in addition for $d\left(z_{1}-z_{0}\right) / d \rho^{S}<0$ requires that $\left(z_{1}-\Theta\right)^{2} / \lambda>$ $\theta\left(z_{0}\right)\left(z_{0 w}-z_{1 w}\right)$.

Corollary 5 The effects of a proportional catch-up in the productivity of the South's final goods sector on Northern and Southern welfare are as follows

$$
\begin{aligned}
\frac{d W_{T}^{N}}{d \rho^{S}} & =z_{1} \frac{d \ln w_{T}}{d \rho^{S}}-\left(\frac{z_{0}}{\rho^{S}}-\frac{1}{\rho^{S}} \int_{0}^{z_{0}} \frac{1}{1+\rho^{S}(a(j)-1)} d j\right) \\
\frac{d W_{T}^{S}}{d \rho^{S}} & =-\left(1-z_{1}\right) \frac{d \ln w_{T}}{d \rho^{S}}-\left(\frac{z_{0}}{\rho^{S}}-\frac{1}{\rho^{S}} \int_{0}^{z_{0}} \frac{1}{1+\rho^{S}(a(j)-1)} d j\right)
\end{aligned}
$$

Proof. Applying Lemma 1, Northern welfare is

$$
W_{T}^{N}=z_{1} \ln w_{T}-\int_{0}^{z_{0}} \ln \left(1+\rho^{S}(a(j)-1)\right) d j-\int_{z_{0}}^{z_{1}} \ln b(j) d j
$$

and Southern welfare is

$$
W_{T}^{S}=-\left(1-z_{1}\right) \ln w_{T}-\int_{0}^{z_{0}} \ln \left(1+\rho^{S}(a(j)-1)\right) d j-\int_{z_{0}}^{z_{1}} \ln b(j) d j
$$

Differentiating wrt to $\rho^{S}$ leads to the expressions above.

Proposition 3 (North leaps ahead) When there is technology transfer $\left(z_{1}-z_{0}>0\right)$, a uniform improvement in the productivity of the Northern final goods sector leads to an increase in the North's relative wage. In addition, when $\lambda \geqslant \lambda_{m}$, or when $\lambda<\lambda_{m}$ and $z_{1 w}-z_{0 w}<$ $\left(z_{1}-\Theta\right)^{2} /\left(1-\theta\left(z_{1}\right)\right) \lambda$, it leads to a contraction in technology transfer. 
Proof. The system of equations becomes

$$
\begin{aligned}
a\left(z_{0}\right) & =e+w a_{T}\left(z_{0}\right) \\
\rho^{N} w & =e+w a_{T}\left(z_{1}\right) \\
w & =\left(\frac{1-\left(z_{1}-\Theta\left(w, z_{0}, z_{1}\right)\right)}{z_{1}-\Theta\left(w, z_{0}, z_{1}\right)}\right) \lambda
\end{aligned}
$$

where $\rho^{N}$ is a productivity parameter for the Northern final goods sector, and $\rho^{N}=1$ initially. Totally differentiating the system of equations gives

$$
\begin{aligned}
& {\left[\begin{array}{ccc}
\left(1-\frac{\lambda}{v^{2}} \frac{e}{w} \int_{z_{0}}^{z_{1}} \frac{\theta(j)}{b(j)} d j\right) & \frac{\lambda}{v^{2}} \theta\left(z_{0}\right) & \frac{\lambda}{v^{2}}\left(1-\theta\left(z_{1}\right)\right) \\
\frac{z_{0 w}}{z_{\varepsilon}} & -\frac{1}{z_{0 \varepsilon}} & 0 \\
-\frac{z_{1 w}}{z_{1 \varepsilon}} & 0 & \frac{1}{z_{1 \varepsilon}}
\end{array}\right]\left[\begin{array}{c}
d w \\
d z_{0} \\
d z_{1}
\end{array}\right] } \\
= & {\left[\begin{array}{c}
0 \\
0 \\
-w
\end{array}\right] d \rho^{N} }
\end{aligned}
$$

The determinant is

$$
\Delta=-\frac{1}{z_{0 \varepsilon}} \frac{1}{z_{1 \varepsilon}}\left(1-\frac{\lambda}{v^{2}}\left(\left(1-\theta\left(z_{1}\right)\right) z_{1 w}+\theta\left(z_{0}\right) z_{0 w}+\frac{e}{w} \int_{z_{0}}^{z_{1}} \frac{\theta(j)}{b(j)} d j\right)\right)>0 \text { by (A3) }
$$

Applying Cramer's Rule then

$$
\begin{aligned}
\frac{d w}{d \rho^{N}} & =-\frac{1}{\Delta} \frac{\lambda}{v^{2}}\left(1-\theta\left(z_{1}\right)\right) w \frac{1}{z_{0 \varepsilon}}<0 \\
\frac{d z_{0}}{d \rho^{N}} & =-\frac{1}{\Delta}\left(\frac{\lambda}{v^{2}}\left(1-\theta\left(z_{1}\right)\right) \frac{z_{0 w}}{z_{0 \varepsilon}} w\right)<0 \\
\frac{d z_{1}}{d \rho^{N}} & =\frac{1}{\Delta}\left(\left(1-\frac{\lambda}{v^{2}} \frac{e}{w} \int_{z_{0}}^{z_{1}} \frac{\theta(j)}{b(j)} d j\right) \frac{1}{z_{0 \varepsilon}} w+\frac{\lambda}{v^{2}} \theta\left(z_{0}\right) \frac{z_{0 w}}{z_{0 \varepsilon}} w\right) \gtrless 0 \\
\frac{d z_{1}}{d \rho^{N}}-\frac{d z_{0}}{d \rho^{N}} & =\frac{1}{\Delta} \frac{1}{z_{0 \varepsilon}} w\left(1+\frac{\lambda}{v^{2}}\left(z_{0 w}\left(1-\theta\left(z_{1}\right)\right)+z_{0 w} \theta\left(z_{0}\right)\right)-\frac{e}{w} \int_{z_{0}}^{z_{1}} \frac{\theta(j)}{b(j)} d j\right)
\end{aligned}
$$

When $\lambda \geqslant \lambda_{m}$ and so $z_{0 w} \geqslant z_{1 w}$ then from (A3) and (64) it follows that $d\left(z_{1}-z_{0}\right) / d \rho^{N}<0$. When $\lambda<\lambda_{m}$ then $z_{1 w}>z_{0 w}$ and in addition in order for $d\left(z_{1}-z_{0}\right) / d \rho^{S}<0$ requires that $\left(z_{1}-\Theta\right)^{2} / \lambda \geqslant\left(1-\theta\left(z_{1}\right)\right)\left(z_{1 w}-z_{0 w}\right)$. 
Corollary 6 The effects of a uniform improvement in the productivity of the North's final goods sector on Northern and Southern welfare are as follows:

$$
\begin{aligned}
\frac{d W^{N}}{d \rho^{N}} & =z_{1} \frac{d \ln w_{T}}{d \rho^{N}}-\frac{\left(1-z_{1}\right)}{\rho^{N}}>0 \\
\frac{d W^{S}}{d \rho^{N}} & =-\left(1-z_{1}\right) \frac{d \ln w_{T}}{d \rho^{N}}-\frac{\left(1-z_{1}\right)}{\rho^{N}} \gtreqless 0
\end{aligned}
$$

Proof. Applying Lemma 1, Northern welfare is

$$
W_{T}^{N}=z_{1} \ln w_{T}-\left(1-z_{1}\right) \ln \rho^{N}-\int_{0}^{z_{0}} \ln a(j) d j-\int_{z_{0}}^{z_{1}} \ln b(j) d j
$$

and Southern welfare is

$$
W_{T}^{S}=-\left(1-z_{1}\right) \ln w_{T}-\left(1-z_{1}\right) \ln \rho^{N}-\int_{0}^{z_{0}} \ln a(j) d j-\int_{z_{0}}^{z_{1}} \ln b(j) d j
$$

Differentiating wrt to $\rho^{N}$ leads to the expressions above.

\subsubsection{Spillovers}

Lemma Spillovers Suppose that spillover benefits for good $j \in\left[z_{0}, z_{1}\right)$ are (increasing) (constant) (decreasing) in $j$, and are proportional to $j^{\beta}, \beta(>)(=)(<) 0$. Then the total spillover benefit to technology transfer $B=\int_{z_{0}}^{z_{1}} j^{\beta} d j$ is maximized at $\lambda_{B}(>)(=)(<) \lambda_{m}$.

Proof. $B$ is maximized at $d B / d w=0$ where $B=\int_{z_{0}}^{z_{1}} j^{\beta} d j=\left(z_{1}^{\beta+1}-z_{0}^{\beta+1}\right) /(\beta+1)$. The maximum spillover benefit occurs at $w_{B}$ which is defined by

$$
\frac{z_{1 w}\left(w_{B}, \varepsilon, \gamma\right)}{z_{0 w}\left(w_{B}, \varepsilon, \gamma\right)}=\left(\frac{z_{0}\left(w_{B}, \varepsilon, \gamma\right)}{z_{1}\left(w_{B}, \varepsilon, \gamma\right)}\right)^{\beta}
$$

From the properties of $z_{0}(w, \varepsilon, \gamma)$ and $z_{1}(w, \varepsilon, \gamma)$, from Lemma 5 which determines $\lambda_{m}$, and since for $w=h(w, \varepsilon, \gamma) \lambda$ for each solution $w$ there is a unique $\lambda$, then

$$
\begin{aligned}
z_{0 w}(w, \varepsilon, \gamma) & >z_{1 w}(w, \varepsilon, \gamma) \text { for } w>w_{m} \Longrightarrow \lambda>\lambda_{m} \\
z_{0 w}(w, \varepsilon, \gamma) & =z_{1 w}(w, \varepsilon, \gamma) \text { for } w=w_{m} \Longrightarrow \lambda=\lambda_{m} \\
z_{0 w}(w, \varepsilon, \gamma) & <z_{1 w}(w, \varepsilon, \gamma) \text { for } w<w_{m} \Longrightarrow \lambda<\lambda_{m}
\end{aligned}
$$

If $\beta>0$ then $\frac{z_{1 w}\left(w_{B}, \varepsilon, \gamma\right)}{z_{0 w}\left(w_{B}, \varepsilon, \gamma\right)}<1$ and $w_{B}>w_{m}$. If $\beta=0$ then $\frac{z_{1 w}\left(w_{B}, \varepsilon, \gamma\right)}{z_{0 w}\left(w_{B}, \varepsilon, \gamma\right)}=1$ and $w_{B}=w_{m}$. If $\beta<0$ then $\frac{z_{1 w}\left(w_{B}, \varepsilon, \gamma\right)}{z_{0 w}\left(w_{B}, \varepsilon, \gamma\right)}>1$ and $w_{B}<w_{m}$. Since from (11) there is a unique mapping between $\lambda$ and $w$, 
which is increasing, then it follows that when $\beta(>)(=)(<) 0$ then $\lambda_{B}(>)(=)(<) \lambda_{m}$.

\subsection{Welfare and Prices}

\subsubsection{Global Welfare}

Lemma 6 Technology transfer leads to an increase in world real income, which is determined by

$$
\ln \left(\frac{Y_{T}}{P_{T}}\right)-\ln \left(\frac{Y_{D}}{P_{D}}\right) \approx \int_{z_{0}}^{z_{D}}(\ln a(j)-\ln b(j)) d j+\int_{z_{D}}^{z_{1}}\left(\ln w_{T}-\ln b(j)\right) d j>0
$$

Proof. Totally differentiating the expression for world income $Y=w L^{N}+L^{S}$ gives

$$
\left(1-z_{D}\right) \frac{d w}{w} \approx \frac{d Y}{Y}
$$

and hence ${ }^{26}$

$$
\left(1-z_{D}\right) \ln \left(\frac{w_{T}}{w_{D}}\right) \approx \ln \left(\frac{Y_{T}}{Y_{D}}\right)
$$

Since the difference between the price level in the post- and pre-technology transfer equilibria is

$$
\ln P_{T}-\ln P_{D}=-\left(1-z_{D}\right) \ln \frac{w_{T}}{w_{D}}+\int_{z_{0}}^{z_{D}}(\ln a(j)-\ln b(j)) d j+\int_{z_{D}}^{z_{1}}\left(\ln w_{T}-\ln b(j)\right) d j
$$

then substituting (65) into (66) gives

$$
\ln \left(\frac{Y_{T}}{P_{T}}\right)-\ln \left(\frac{Y_{D}}{P_{D}}\right) \approx \int_{z_{0}}^{z_{D}}(\ln a(j)-\ln b(j)) d j+\int_{z_{D}}^{z_{1}}\left(\ln w_{T}-\ln b(j)\right) d j>0
$$

and world income $Y_{i}$ deflated by the price index $P_{i} \quad$ (for $i=T, D$ ) increases between the pre- and post-technology transfer situations. This is approximately equal because the movement between the pre- and post-technology transfer situations is a discrete change.

\subsubsection{Welfare in the North and South}

Welfare in the North in the DFS equilibrium is

$$
W_{D}^{N}=\ln w_{D}-\int_{0}^{1} \ln p_{D}(j)=\ln w_{D}-\int_{0}^{z_{D}} \ln a(j) d j-\int_{z_{D}}^{1} \ln w_{D} d j=z_{D} \ln w_{D}-\int_{0}^{z_{D}} \ln a(j) d j
$$

\footnotetext{
${ }^{26}$ Since for small $x, \ln (1+x) \approx x$ then $\frac{d w}{w} \approx \ln \left(1+\frac{w_{T}-w_{D}}{w_{D}}\right)=\ln \frac{w_{T}}{w_{D}}$ and $\frac{d Y}{Y} \approx \ln \frac{Y_{T}}{Y_{D}}$.
} 
while in the technology transfer equilibrium welfare it is given by (42). The change in welfare in the North between the post- and pre- technology transfer equilibria is

$$
\Delta W_{T-D}^{N}=W_{T}^{N}-W_{D}^{N}=z_{D} \ln \frac{w_{T}}{w_{D}}+\int_{z_{0}}^{z_{D}}(\ln a(j)-\ln b(j)) d j+\int_{z_{D}}^{z_{1}}\left(\ln w_{T}-\ln b(j)\right) d j
$$

Welfare in the South in the DFS equilibrium is

$$
W_{D}^{S}=-\int_{0}^{1} p_{D}(j)=-\int_{0}^{z_{D}} \ln a(j) d j-\int_{z_{D}}^{1} \ln w_{D} d j=-\left(1-z_{D}\right) \ln w_{D}-\int_{0}^{z_{D}} \ln a(j) d j
$$

while in the technology transfer equilibrium welfare it is given by (43). The change in welfare in the South between the post- and pre- technology transfer equilibria is

$$
\Delta W_{T-D}^{S}=W_{T}^{S}-W_{D}^{S}=-\left(1-z_{D}\right) \ln \frac{w_{T}}{w_{D}}+\int_{z_{0}}^{z_{D}}(\ln a(j)-\ln b(j)) d j+\int_{z_{D}}^{z_{1}}\left(\ln w_{T}-\ln b(j)\right) d j
$$

Lemma 7 The North is better off in the technology transfer equilibrium than under autarky, since

$$
\Delta W_{T-A}^{N}=W_{T}^{N}-W_{A}^{N}=\int_{0}^{z_{0}}\left(\ln w_{T}-\ln a(j)\right) d j-\int_{z_{0}}^{z_{1}}\left(\ln w_{T}-\ln b(j)\right) d j>0
$$

Proof. The North's welfare per capita under autarky is zero since

$$
W_{A}^{N}=\ln w_{A}-\int_{0}^{1} \ln p_{A}(j)=\ln w_{A}-\int_{0}^{1} \ln w_{A}=0
$$

while the North's welfare under technology transfer is given by (42). The change in welfare between the technology transfer equilibrium and autarky is thus given by

$$
W_{T}^{N}-W_{A}^{N}=W_{T}^{N}
$$

Hence the North is better off under the technology transfer equilibrium than under autarky.

Lemma 8 The South is better off when technology transfer is costless, in which case they have Northern technology and are in autarky, than when technology transfer is costly since

$$
W_{T}^{S}-W_{A^{*}}^{S}=-\left(1-z_{1}\right) \ln w_{T}-\int_{z_{A}}^{z_{0}} \ln a(j) d j-\int_{z_{0}}^{z_{1}} \ln b(j) d j<0
$$

Proof. Under autarky with Northern technology, indicated by $A^{*}$, welfare in the South is

$$
W_{A^{*}}^{S}=-\int_{0}^{1} \ln p_{A}(j)=-\int_{0}^{1} \ln 1 d j=0
$$


while in the technology transfer equilibrium Southern welfare is given (43). Taking the difference gives

$$
W_{T}^{S}-W_{A^{*}}^{S}=W_{T}^{S}<0
$$

\subsubsection{Prices}

Since $W_{i}^{S}=-\ln P_{i}$ for $i=D, T$ the difference between the price level in the post- and pretechnology transfer equilibria is $-\Delta W_{T-D}^{S}$, and is given in (66).

\subsection{Technology Transfer and Intellectual Property Rights}

To determine an expression for the balance of trade we examine South's labour market equilibrium $L^{S}=\left(z_{1}-\Theta\right) Y$. Northern income is now $w L^{N}+\phi Y$, and therefore

$$
\begin{aligned}
Y= & w L^{N}+\phi Y+L^{S} \\
& \quad \text { which may be rearranged } \\
Y= & \frac{w L^{N}+L^{S}}{1-\phi}
\end{aligned}
$$

Substituting into the expression for South's labour market equilibrium leads to

$$
w=\frac{1-\phi-\left(z_{1}-\Theta\right)}{z_{1}-\Theta}
$$

\section{References}

Aitken, B. J. and A.E. Harrison, "Do Domestic Firms Benefit from Direct Foreign Investment? Evidence from Venezuela," American Economic Review, 89(3) (1999), 605-618.

Baldwin, R. and F. Robert-Nicoud, 2007, "Offshoring: General Equilibrium Effects on Wages, Production and Trade," NBER Working Paper No. 12991.

Cheng, L. K., L.D. Qui, G. Tan, "Foreign direct investment and international trade in a continuum Ricardian trade model," Journal of Development Economics, 77 (2005), 477-501.

Coe, D.T., E. Helpman, and A.W. Hoffmaister, "North-South R \& D Spillovers," Economic Journal, 107 (1997), 134-149.

Cohen, W.M. and D.A. Levinthal, "Innovation and learning: The two faces of R\&D," Economic Journal, 94 (1989), 569-596. 
Damijan, Joze P., M. Knell, B. Majcen and M. Rojec, "The role of FDI, R\&D accumulation and trade in transferring technology to transition countries: evidence from firm panel data for eight transition countries," Economic Systems, 27 (2003), 189-204.

Djankov, S. and B. Hoekman, "Foreign Investment and Productivity Growth in Czech Enterprises," World Bank Economic Review, 14(1) (2000), 49-64.

Dornbusch, R., S. Fischer, and P. Samuelson, "Comparative Advantage, Trade and Payments in a Ricardian Model with a Continuum of Goods," American Economic Review, 67 (1977), 823-39.

Gancia, G. and A. Bonfiglioli, "North-South trade and directed technical change," Journal of International Economics, 76 (2008), 276-295.

Glass, A.J., and K. Saggi, 2008, "The Role of Foreign Direct Investment in International Technology Transfer," in A. K. Dutt, J. Ros, eds, International Handbook of Development Economics, Vol. II (Edward Elgar, 2009).

Grossman, G., and E. Rossi-Hansberg, "Trading Tasks: A Simple Theory of Offshoring," American Economic Review, 98(5) (2008), 1978-1997.

Grossman, G., and E. Helpman," "Innovation and growth in the global economy," (Cambridge: MIT Press, 1991).

Haddad, Mona and A. E. Harrison, "Are There Positive Spillovers from Direct Foreign Investment: Evidence from Panel Data for Morocco," Journal of Development Economics, 42(1) (1993), $51-74$.

Javorcik, B. S., "Does Foreign Direct Investment Increase the Productivity of Domestic Firms? In Search of Spillovers through Backward linkages," American Economic Review 94 (2004), 605-627.

Jones, R. W., and R. Ruffin, "International Technology Transfer: Who Gains and Who Loses?," Review of International Economics, 75(2) (2007), 321-328.

Jones, R. W., and R. Ruffin, "The Technology Transfer Paradox," Journal of International Economics, 15(2) (2008), 209-222.

Kinoshita, Y., "R\&D and Technology Spillovers via FDI: Innovation and Absorptive Capacity," CEPR Discussion Paper No. 2775, 2000.

Konings, J. and A. Murphy, "Do Multinational Enterprises Substitute Parent Jobs for Foreign Ones? Evidence from European Firm-Level Panel Data," CEPR Discussion Paper No. 2972, 2001.

Krugman, P., "A Model of Innovation, Technology Transfer, and the World Distribution of Income," Journal of Political Economy, 87(2) (1979), 253-266. 
Leahy, D., and J.P. Neary, "Absorptive capacity, R \& D spillovers, and public policy," International Journal of Industrial Organization, 25 (2007), 1089-1108.

Mussa, M., "Dyanmic Adjustment in the Heckscher-Ohlin-Samuelson Model," Journal of Political Economy, 86(5) (1978), 775-791.

Rodriguez-Clare, A., "Offshoring in a Ricardian World," American Economic Journal: Macroeconomics, 2(2) (2010), 227-258.

Samuelson, P. A., "Where Ricardo and Mill Rebut and Confirm Arguments of Mainstream Economists Supporting Globalization," Journal of Economic Perspectives, 18(3) (2004), 135-46.

Teece, D.J., "Technology Transfer by Multinational Firms: The Resource Cost of Transferring Technological Know-How," Economic Journal, 87 (1977), 242-261.

Young, A., "Learning By Doing and the Dynamic Effects of International Trade," Quarterly Journal of Economics, 106 (1991), 369-405. 